\title{
Which substances loaded onto collagen scaffolds influence oral tissue regeneration?-an overview of the last 15 years
}

\author{
Michael Edelmayer ${ }^{1,2,3}$ (D) Christian Wehner ${ }^{2,4} \cdot$ Christian Ulm $^{1} \cdot$ Werner Zechner ${ }^{1} \cdot$ David Shafer $^{3} \cdot$ Hermann Agis $^{2,4}$
}

Received: 18 June 2020 / Accepted: 10 August 2020 / Published online: 22 August 2020

(C) The Author(s) 2020

\begin{abstract}
Background Collagen scaffolds are widely used for guided bone or tissue regeneration. Aiming to enhance their regenerative properties, studies have loaded various substances onto these scaffolds. This review aims to provide an overview of existing literature which conducted in vitro, in vivo, and clinical testing of drug-loaded collagen scaffolds and analyze their outcome of promoting oral regeneration.

Materials and methods PubMed, Scopus, and Ovid Medline ${ }^{\circledR}$ were systematically searched for publications from 2005 to 2019. Journal articles assessing the effect of substances on oral hard or soft tissue regeneration, while using collagen carriers, were screened and qualitatively analyzed. Studies were grouped according to their used substance type — biological medical products, pharmaceuticals, and tissue-, cell-, and matrix-derived products.

Results A total of 77 publications, applying 36 different substances, were included. Collagen scaffolds were demonstrating favorable adsorption behavior and release kinetics which could even be modified. BMP-2 was investigated most frequently, showing positive effects on oral tissue regeneration. BMP-9 showed comparable results at lower concentrations. Also, FGF2 enhanced bone and periodontal healing. Antibiotics improved the scaffold's anti-microbial activity and reduced the penetrability for bacteria.

Conclusion Growth factors showed promising results for oral tissue regeneration, while other substances were investigated less frequently. Found effects of investigated substances as well as adsorption and release properties of collagen scaffolds should be considered for further investigation.

Clinical relevance: Collagen scaffolds are reliable carriers for any of the applied substances. BMP-2, BMP-9, and FGF2 showed enhanced bone and periodontal healing. Antibiotics improved anti-microbial properties of the scaffolds.
\end{abstract}

Keywords Collagen $\cdot$ Dentistry $\cdot$ Oral surgery $\cdot$ Maxillofacial surgery $\cdot$ Periodontics

\section{Introduction}

Collagen is an important biomaterial which is frequently applied in oral and maxillofacial tissue engineering and

Michael Edelmayer

michael.edelmayer@meduniwien.ac.at

1 Clinical Division of Oral Surgery, University Clinic of Dentistry, Medical University of Vienna, Vienna, Austria

2 Austrian Cluster for Tissue Regeneration, Vienna, Austria

3 Department of Craniofacial Sciences, Division of Oral \& Maxillofacial Surgery, School of Dental Medicine, University of Connecticut, Farmington, CT, USA

4 Clinical Division of Conservative Dentistry and Periodontology, University Clinic of Dentistry, Medical University of Vienna, Vienna, Austria regenerative medicine approaches that aim to restore, maintain, or enhance damaged or substantially reduced tissues $[1$, 2]. Different fields in dentistry face specific objectives referring to hard and soft tissue regeneration, and collagen has been successfully implemented into various treatment strategies [2, $3]$. As the main component of extracellular matrix (ECM), collagen is essential for the structural maintenance of oral tissues and plays an important role in numerous cellular processes $[4,5]$. In tissue engineering application, collagen exhibits excellent biocompatibility and low antigenicity [6]. As collagen is biodegradable and shows poor mechanical properties, non-enzymatic or enzymatic cross-linking procedures using glutaraldehyde or formaldehyde for example can be performed to modify collagen membranes. Consequently, these procedures prevent rapid degradation and enhance mechanical properties $[7,8]$. Collagen membranes are used in guided tissue regeneration (GTR) and guided bone 
regeneration (GBR), which are methods used in oral surgery as augmentative techniques. Both GBR and GTR are based on the principle to cover periodontal epithelium and bone as well as to maintain the tissue defect space in order to exclude epithelium and gingival connective tissue due to their faster growing properties compared with hard tissue. While GTR focuses on regenerating soft tissue of the periodontal attachment, GBR, in addition, is aiming to support new bone tissue growth [9]. Favorable properties of a membrane include biocompatibility, impermeability for epithelial cells or bacteria, and adequate mechanical properties to allow proper handling during surgery and stiffness for space maintenance and less pressure to the bone graft during healing. Also, the time of resorption should allow the bone graft to regenerate, before degradation of the membrane causes the loss of the stated properties. In the beginning of GTR development, a bacterial filter consisting of cellulose acetate was placed over the treated area to serve as an occlusive membrane [10]. Aiming to improve clinical application, further studies investigated the use of nonresorbable expanded polytetrafluorethylen (e-PTFE) in membranes, which could also have been reinforced by titanium. Although mechanical stability can be enhanced using titanium, a second surgical entry is required to remove the membrane [11]. The next generation of barrier membranes were focused on resorbable materials, including collagen, to avoid a surgical removal [12]. Further advances aimed to improve the regeneration process and wound healing, and to serve as local drug carriers. To release specific substances at the wound site, collagen membranes can be loaded with various agents, such as antibiotics, growth factors, or adhesion molecules [13]. Progress in the field of tissue engineering has resulted in the development of innovative scaffold designs that act as a biological platform to enable reparation and restoration of injured tissues during the healing process. Collagen can easily be used to build 3D scaffolds and sponges, and can also serve as a carrier for the delivery of substances, such as growth factors or bone morphogenetic proteins, aiming to enhance healing and support regeneration [14].

In the past years, the number of publications investigating the role of drug-loaded collagen scaffolds in tissue engineering has increased, indicating a growing interest in this topic. The primary aim of this review is to give an overview of different cell-free regenerative approaches which utilize collagen as a biomaterial carrier by summarizing existing studies from the past 15 years. At the time of creating this publication, there was no existing literature reviewing this topic. The secondary aim was to provide information about the outcome of those studies according to their influence on oral tissue regeneration. This information could allow suggestions of future applications in dentistry and oral surgery or the need for further research.

\section{Materials and methods}

\section{Study design}

A study protocol for a qualitative literature review was developed by all authors based on recommended methods [15]. The focused PICO (problem, intervention, comparison, outcome) question was: Does loading of substances onto collagen scaffolds influence oral tissue regeneration parameters in vitro and/or in vivo, compared with unloaded control? The whole review process was designed according to the Preferred Reporting Items for Systematic Reviews and Meta-Analyses (PRISMA) Statement [16].

\section{Inclusion and exclusion criteria}

Literature research was performed by applying specific search terms, aiming to find publications about drug-loaded collagen scaffolds with the purpose to promote oral soft or hard tissue regeneration. Journal articles published from January 1, 2005 to December 31, 2019 with original data from in vitro and/or in vivo and/or clinical testing were included. Reasons for exclusion were review articles, cell-based therapeutic approaches, if the collagen scaffold was not loaded, if other biomaterials than collagen were used as substance carriers, or if the study did not reflect the topic of this review. Aiming to widen the scope of this review and to be able to discuss articles which primarily focused on release properties without using negative controls, we did not exclude studies without unloaded collagen scaffolds as control group.

\section{Search strategy}

Three scientific databases-PubMed, Scopus, and Ovid Medline ${ }^{\circledR}$ - were used for the search. The following search term was used: "("collagen" AND ("loaded" OR "soaked") AND ("dentistry" OR "oral surgery" OR "maxillofacial surgery" OR "periodontics" OR "periodontology"))". Filters or limits for publication date starting from January 1, 2005 to December 31, 2019, language (English), and type of article (original journal article) were applied. References of each publication were searched for additional records.

\section{Study selection}

Duplicates were automatically removed, and remaining papers were manually screened for their content. Publications were then selected according to the inclusion and exclusion criteria. Studies were subdivided - depending on utilized substances - into biological medical products, pharmaceuticals, and tissue-, cell-, and matrix-derived products. 


\section{Data Extraction}

Two authors independently extracted data from the full texts of included articles, using specifically designed tables. Descriptive summaries were entered, and a qualitative synthesis was conducted. Data extracted were author(s), study design, substance, type of collagen scaffold, aim(s), methods, and outcomes or main findings.

\section{Risk of bias and quality assessment}

The risk of bias and the quality of the included studies was assessed independently by two authors according to the revised recommendation of the CONSORT statement. After scores were calculated, an overall estimation risk of bias (low, all criteria met; moderate, one or more criteria partly met; or high, one or more criteria were not met) was performed for each selected study. Any disagreement between the reviewers during study selection, data extraction, and quality assessment was resolved by discussion until consensus among all authors was reached. For in vitro and in vivo studies, no further risk of bias was assessed as no validated bias risk assessment tool was available.

\section{Results}

\section{Search results and study characteristics}

The initial search procedure using PubMed $(n=248)$, Scopus $(n=56)$, and Ovid Medline ${ }^{\circledR}(n=20)$ led to 324 search results overall. After discarding of duplicates, the total findings were reduced to 259 unique journal articles. Following the inclusion and exclusion criteria, 182 studies had to be excluded leading to a total of 77 , which were further investigated and later synthesized in this review (Fig. 1).

Out of these 182 excluded studies, 4 were review articles, 22 were using cell-based approaches, and 28 used collagen scaffolds but did not load them with their substance as they mostly used a collagen membrane only as a cover. Another 53 articles were evaluating different aspects like mechanical testing, implant survival after alveolar socket preservation and implant placement, systemic therapy, and others. From 72 studies which utilized other biomaterials than collagen as drug carriers, 18 were actually using collagen but in a mixed combination with deproteinized bovine bone mineral (DBBM), a widely used type of scaffold in dentistry and oral surgery (Fig. 1). The timeline of the past 15 years reveals a steadily increasing number of scientific publications in this field. Starting from zero to three publications from 2005 to 2010, to around 10 publications per year in the last 5 years (Fig. 2).

In all included publications, in vitro and in vivo testing was performed in $34 \%(n=32)$ and $55 \%(n=52)$, respectively.
Clinical testing of loaded collagen was carried out in only $11 \%(n=10)$ of the publications, where BMP-2, doxycycline, alendronate, simvastatin, and platelet-rich fibrin have been tested in humans.

\section{Drug types and types of collagen scaffolds}

All of the 77 included studies were assigned to subgroups according to their defined category: biological medical products, pharmaceuticals, or tissue-, cell-, and matrix-derived products (Table 1).

The numerical values show how often the specific substance was used in one of the 77 studies

In total, 36 different drugs were utilized as therapeutic agents in 77 included publications. Biologicals were the most frequently used substance-category $(n=60)$, followed by pharmaceuticals $(n=27)$ and tissue-, cell-, and matrixderived products $(n=10)$. BMP-2 $(n=33)$, followed by FGF2 $(n=5)$ and BMP-9 $(n=4)$ together with SDF-1 $(n=$ 4) were to most often used substances. Looking at the types of collagen scaffolds which were utilized as carrier materials, sponges, or matrices were used in 50 , membranes in 23 , and gels in only 4 studies (Tables 2, 3, and 4).

\section{Risk of bias and quality of the included studies}

Sixty-seven out of 77 included studies were conducting in vitro and in vivo testing which are regarded as the lowest level of evidence. Ten out of 67 pre-clinical studies did not use unloaded collagen scaffolds as control. These studies utilized different substance dosages as positive control [40, 63, 68, 82], other substances [64, 85], blood clot formation after surgical interventions $[33,39]$, or no control group at all $[23,66]$. Four out of ten clinical studies were case series with five to ten patients $[46-48,89]$, whereas one was a pilot study with 12 patients [90] and five were clinical trials with 20 to 64 patients $[45,49,69,71,76]$. Eight out of ten clinical studies did not use an unloaded collagen scaffold as control [45-49, 69, 89, 90]. A CONSORT-based quality analysis of the ten included clinical studies showed a high risk of bias due to missing sample size calculation, unreported or missing methods of randomization and allocation concealment, incompleteness of followup, and lack of masking.

\section{Biological medical products}

Biopharmaceuticals or biological medical products are manufactured pharmaceutical drugs which are semisynthesized or extracted from biological sources. This drug category was most commonly applied in the included studies (Table 1). The following table lists all studies which used different biological medical products loaded onto different types of collagen scaffolds (Table 2). 
Fig. 1 Flow diagram of the review process according to Preferred Reporting Items for Systematic Reviews and MetaAnalyses: The PRISMA

Statement [16]

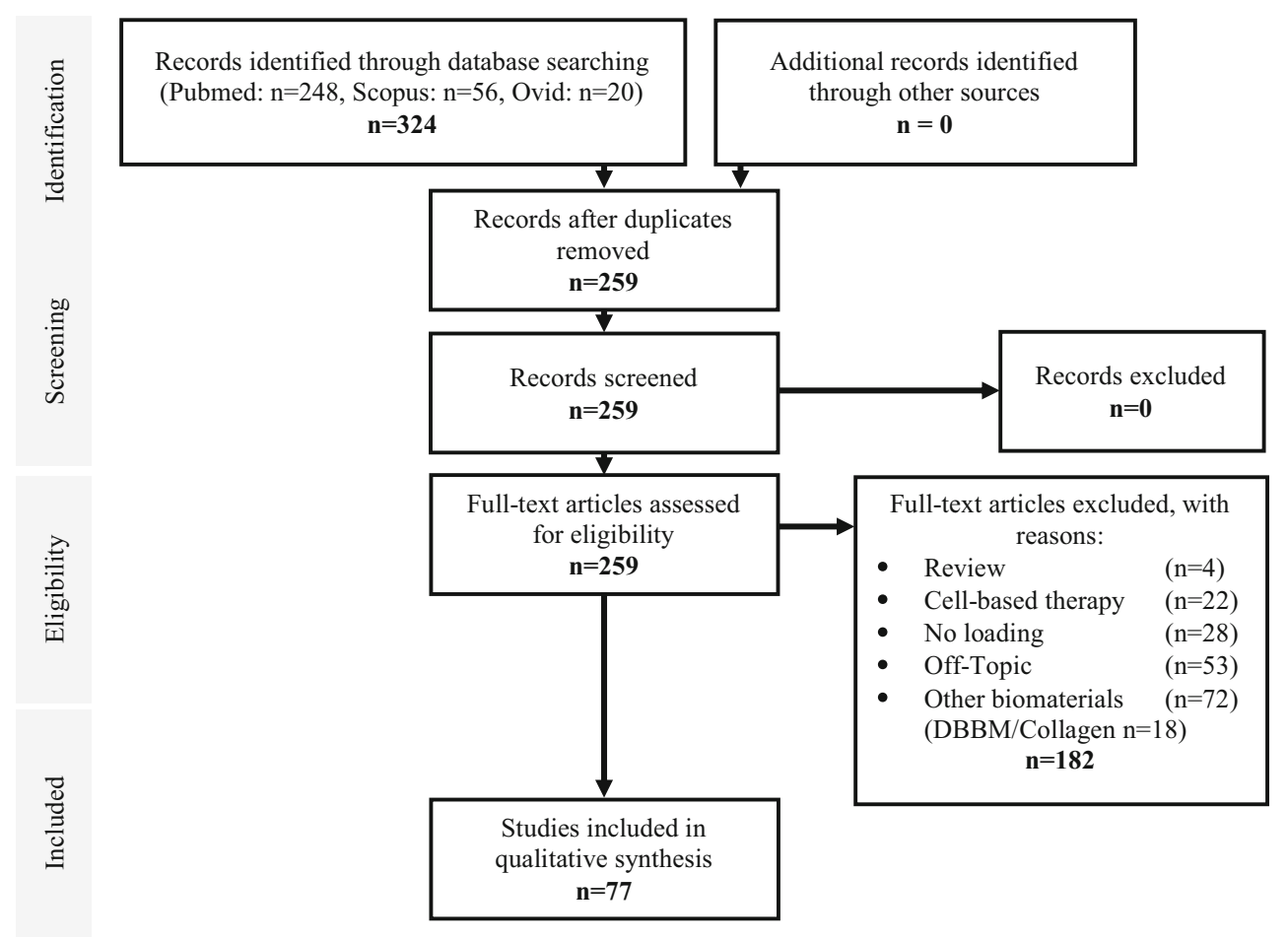

\section{Multifunctional growth and differentiation factors}

- Bone morphogenetic protein-2 (BMP-2)

Collagen membranes loaded with BMP-2 at a concentration of $10 \mathrm{ng} / \mathrm{mL}$ increased human osteoblast proliferation up to 5 days post-seeding. Osteoblast differentiation markers, such as osterix, collagen I, and osteocalcin, were increased and mineralization of primary osteoblasts was pronounced (Miron R.J. et al. 2013 [17]). Another study used BMP-2 loaded collagen gel as control, comparing a designed chitosan-alginate-hydroxyapatite (CAH) scaffold as carrier for BMP-2. Release kinetics revealed a faster release from collagen compared with CAH (84 to $64 \%$ within 7 days). Alkaline phosphatase (ALP) activity and Alizarin red staining were significantly increased in mesenchymal stem cells (MSC) cultured with loaded collagen compared with unloaded CAH. Other results are not included in this review when collagen was not used as the substance carrier and BMP-2 was loaded in combination with MSC in the vivo part of this study (He X. et al. 2014 [18]). When loading BMP-2 at a low $(10 \mathrm{ng} / \mathrm{mL})$ or high $(100 \mathrm{ng} / \mathrm{mL})$ concentration onto collagen membranes, the substance was fully absorbed and slowly released within 10 days. Seeding murine ST2 stromal bone marrow cells onto these scaffolds revealed that ALP mRNA levels were significantly induced at 3 days and bone
Fig. 2 Timeline of included publications per year including a linear trend line demonstrating an increasing number of publications in that field over the past 15 years
Timeline of search results \& included articles per year

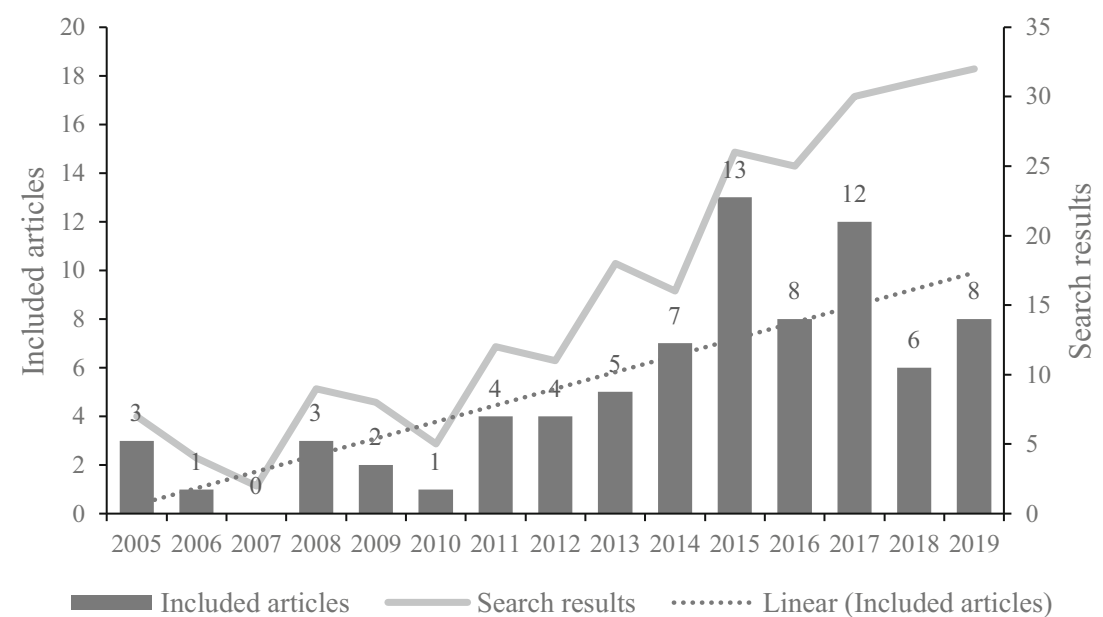


Table 1 Overview of drugs and their categories which have been used in the included articles

\begin{tabular}{|c|c|}
\hline Biological medical products & Count \\
\hline Multifunctional growth and differentiation factors & $\sum=60$ \\
\hline Bone morphogenetic protein-2 (BMP-2) & 33 \\
\hline BOne morphogenetic protein-6 (BMP-6) & 1 \\
\hline Bone morphogenetic protein-7 (BMP-7) & 1 \\
\hline Bone morphogenetic protein-9 (BMP-9) & 4 \\
\hline Erythropoietin (EPO) & 1 \\
\hline Fibroblast growth factor 2 (FGF2) & 5 \\
\hline Human growth hormone (HGH) & 1 \\
\hline Interferon gamma (IFN- $\gamma)$ & 1 \\
\hline Platelet-derived growth factor (PDGF) & 3 \\
\hline Receptor activator of NF-kB ligand (RANKL) & 1 \\
\hline $\begin{array}{l}\text { Stromal cell-derived factor } 1 / \mathrm{C}-\mathrm{X}-\mathrm{C} \text { motif chemokine } 12 \\
\text { (SDF1) }\end{array}$ & 4 \\
\hline Transforming growth factor beta 1 (TGF $\beta 1)$ & 3 \\
\hline Vascular endothelial growth factor (VEGF) & 2 \\
\hline Pharmaceuticals & $\sum=27$ \\
\hline \multicolumn{2}{|l|}{ Antibiotics } \\
\hline$\beta$-Lactam antibiotic (amoxicillin) & 2 \\
\hline Tetracycline (doxycycline) & 3 \\
\hline \multicolumn{2}{|l|}{ Bisphosphonates } \\
\hline Alendronate & 3 \\
\hline \multicolumn{2}{|l|}{ Corticosteroid } \\
\hline Dexamethasone & 1 \\
\hline \multicolumn{2}{|l|}{ Hypoxia mimetic agents } \\
\hline Deferoxamine (DFO) & 2 \\
\hline Dimethyloxalylglycine (DMOG) & 2 \\
\hline L-Mimosine (L-MIM) & 1 \\
\hline \multicolumn{2}{|l|}{ Statin } \\
\hline Simvastatin & 2 \\
\hline \multicolumn{2}{|l|}{ Others } \\
\hline Anti-tumor necrosis factor- $\alpha$ (anti-TNF- $\alpha$ ) & 1 \\
\hline Calendula officinalis flower extract & 1 \\
\hline Cyanoacrylate (CA) & 1 \\
\hline Glycosaminoglycan/hyaluronic acid (GAG/HA) & 3 \\
\hline Human albumin (nitric oxide donor) & 1 \\
\hline Mussel adhesive protein (MAP) & 1 \\
\hline Parathyroid hormone (PTH) & 1 \\
\hline Progranulin (anti-tumor necrosis factor- $\alpha$ ) & 1 \\
\hline Vitamin D & 1 \\
\hline Tissue-, cell-, and matrix-derived products & $\sum=10$ \\
\hline Bone conditioned medium (BCM) & 2 \\
\hline Cell conditioned medium (CCM) & 1 \\
\hline Platelet-rich plasma (PRP) & 2 \\
\hline Platelet-rich fibrin (PRF) & 2 \\
\hline Platelet secretome (PSEC) & 1 \\
\hline Enamel matrix derivative (EMD) & 2 \\
\hline
\end{tabular}

sialoprotein (BSP) at 14 days. Compared with BMP-9 loaded scaffolds, messenger RNA (mRNA) levels of ALP, collagen1, BSP, and osteocalcin were significantly lower in BMP-2 groups. Effects on cell attachment, proliferation, and osteoblast differentiation were not significant. Alizarin red staining was three times less compared with BMP-9 (FujiokaKobayashi M. et al. 2016 [19], Fujioka-Kobayashi M. et al. 2017 [20]). Elastin-like polypeptide-collagen hydrogels were loaded with BMP-2 and doxycycline together. Release of BMP-2 assayed by ELISA showed a linearity over 7 days. Adhesion, proliferation, and migration of human adiposederived stem cells on hydrogel surfaces was higher for drugloaded samples compared with unloaded gels (Pal P. et al. 2019 [21]). In vivo, collagen sponges were soaked with 100 , 500 , or $1000 \mu \mathrm{g} / \mathrm{mL}$ BMP-2 and used in a calvarial defect model in rabbits. After 1 month, height and amount of newly generated tissue were significantly higher at any concentrations of BMP-2. The amount of mineralized bone was only significantly increased in the $1000 \mu \mathrm{g} / \mathrm{mL}$ group compared with control (Hasegawa Y. et al. 2008 [22]). Another study in 2008 used gene transfer in bone marrow stromal cells (BMSC) to promote BMP-2 production. Human BMP-2 complementary DNA (cDNA) was subcloned into the plasmid pcDNA3.1 and BMSCs were transfected with it. Results showed that the level of expressed and secreted BMP-2 was significantly higher in transfected cells than in untransfected cells. Collected cultured medium from transfected BMSCs induced the expression of ALP and osteocalcin in nontransfected cells. When incorporating BMP-2-cDNA3.1 complexes into collagen sponges and implanting them into rabbit calvarial defects at both 4 and 8 weeks, experimental groups showed significantly more newly formed bone. No negative control was utilized (Seol Y.J. et al. 2008 [94]). In a middiaphyseal defect model of diabetic rats, collagen sponges loaded with BMP-2 were inserted. Qualitative microradiography and assessment showed that BMP-2 increased new bone formation after 6 weeks. Histomorphometric analysis revealed a significantly higher area of new bone formation. Histologically, platelet endothelial cell adhesion molecule-1 staining at 3 weeks was higher in BMP-2 treated rats. All defects in the control group without BMP-2 had nonunion, so mechanical testing could only be executed in the BMP-2 group (Azad V. et al. 2009 [24]). Another study used criticalsized calvarial defects as orthotopic model and created subcutaneous pouches in rats as ectopic model. The aim was to assess the effect of collagen sponges loaded with different doses of BMP-2 $(25,50,100$, and $200 \mu \mathrm{g} / \mathrm{mL})$. Bone formation was enhanced at all doses of BMP-2 compared with control. After 2 weeks, bone formation could be observed in the ectopic model which was less at 8 weeks post operatively but showed advanced bone remodeling and maturity (Lee J.H. et al. 2010 [25]). In 2011, a study combined BMP-2 together with glycosaminoglycans (GAG) of biglycan (BGN) on 


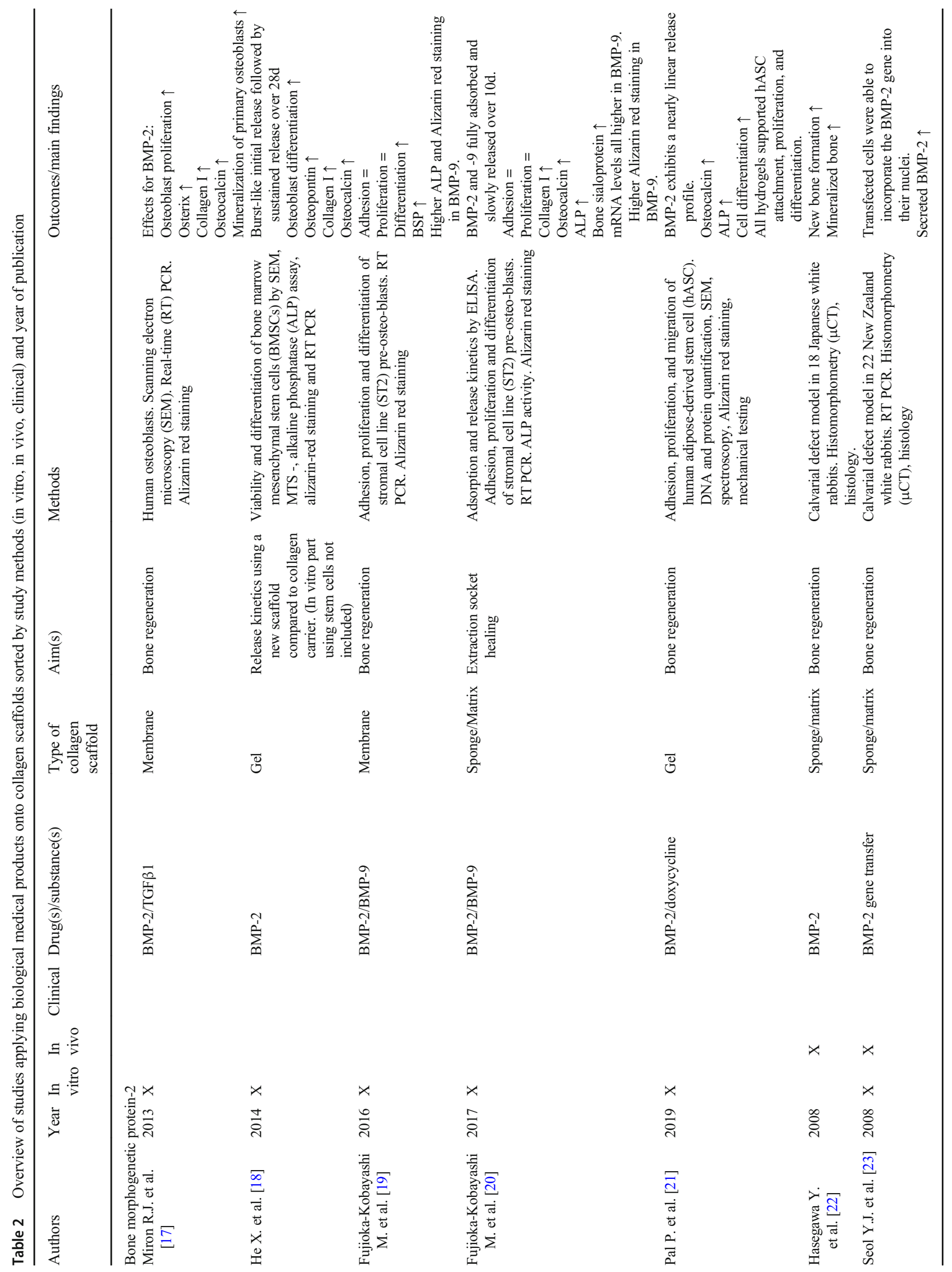




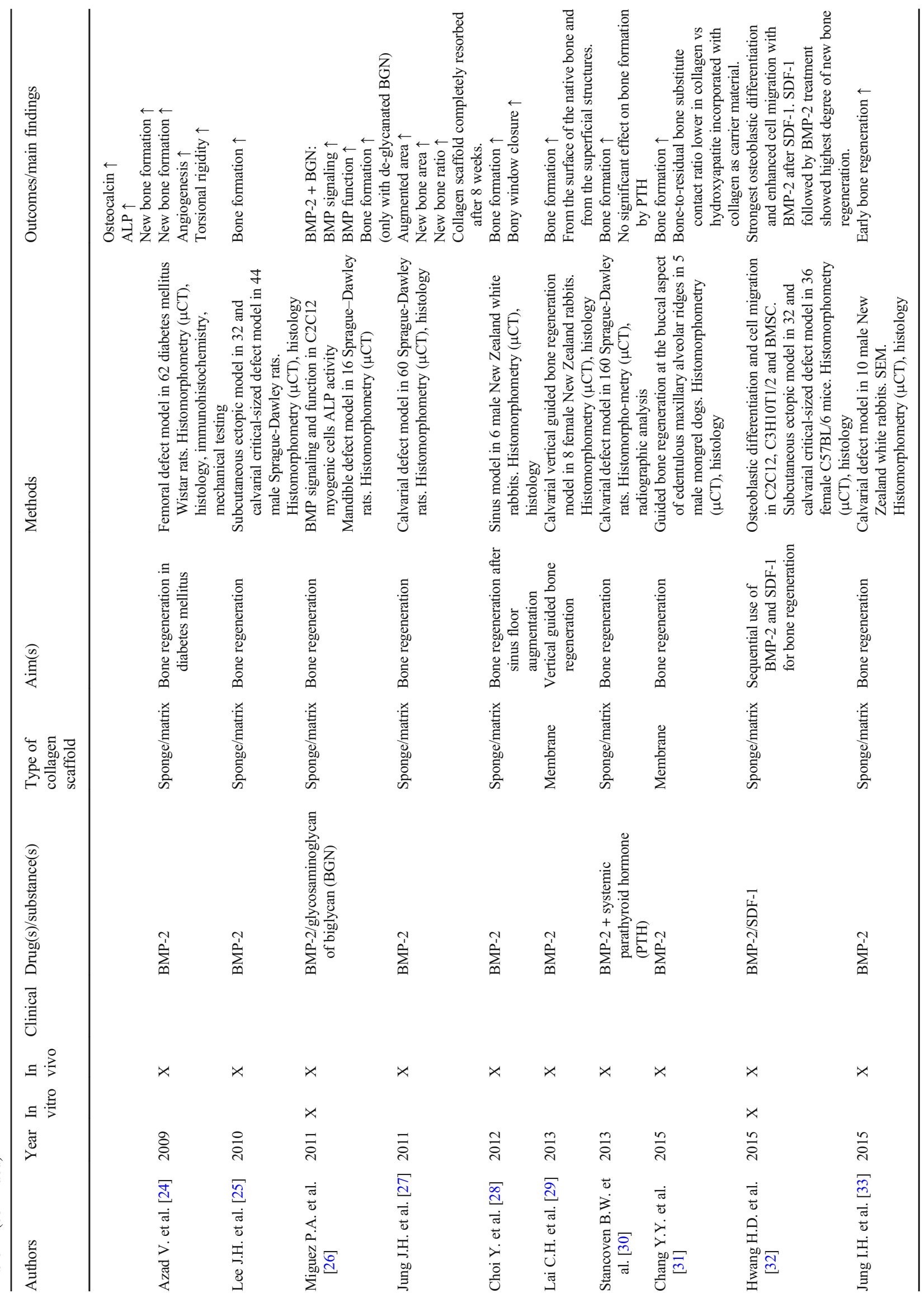




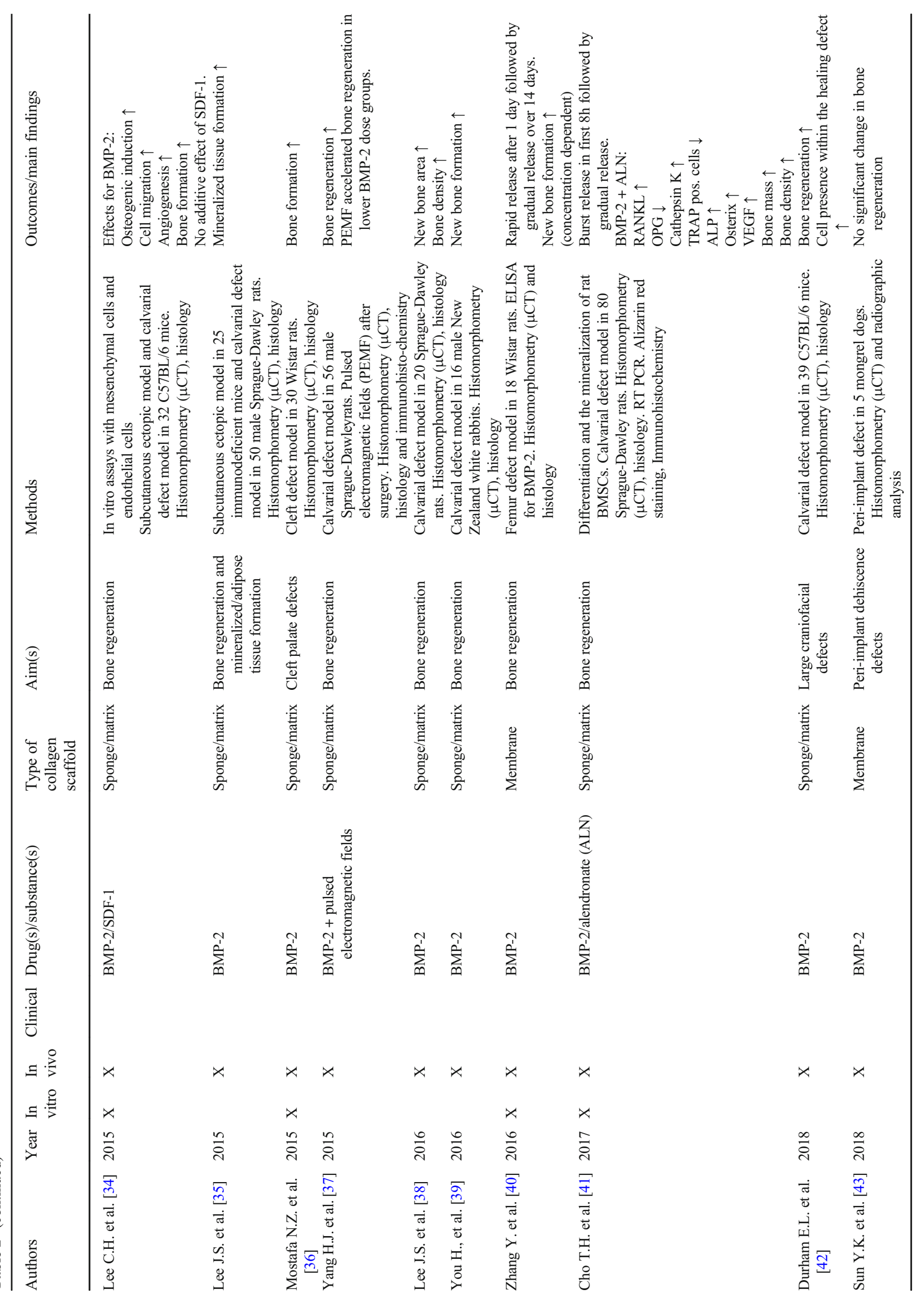




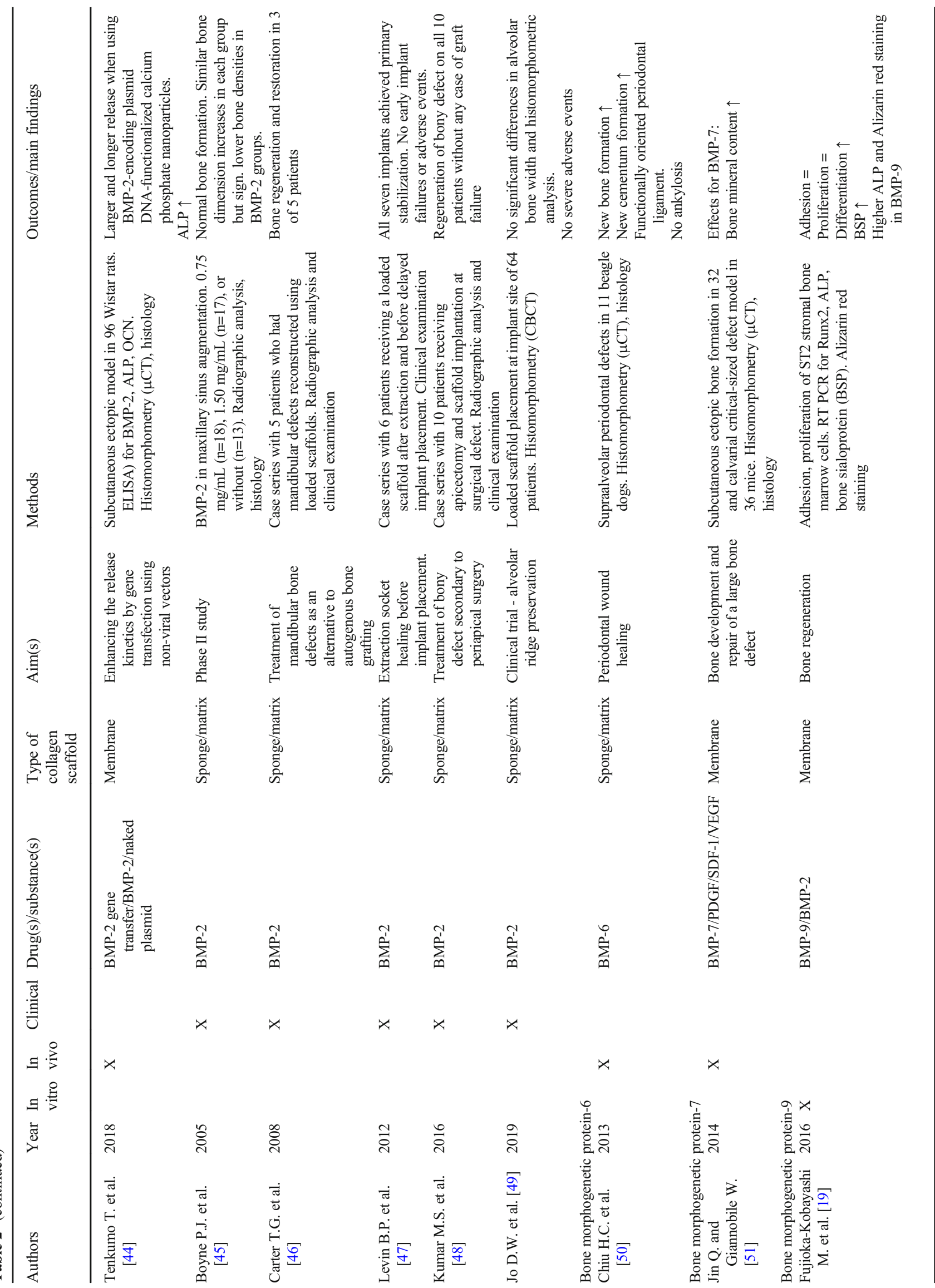




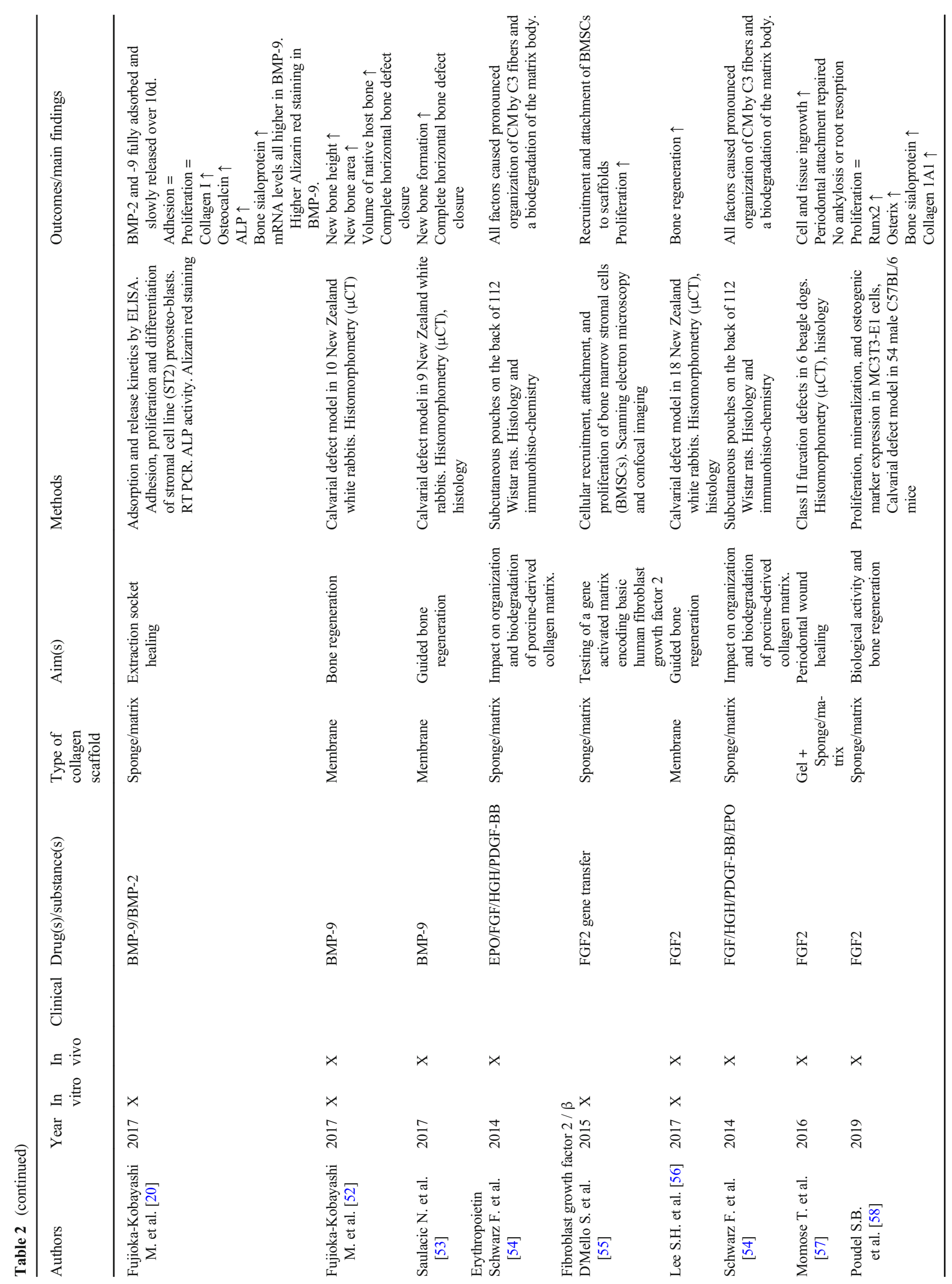




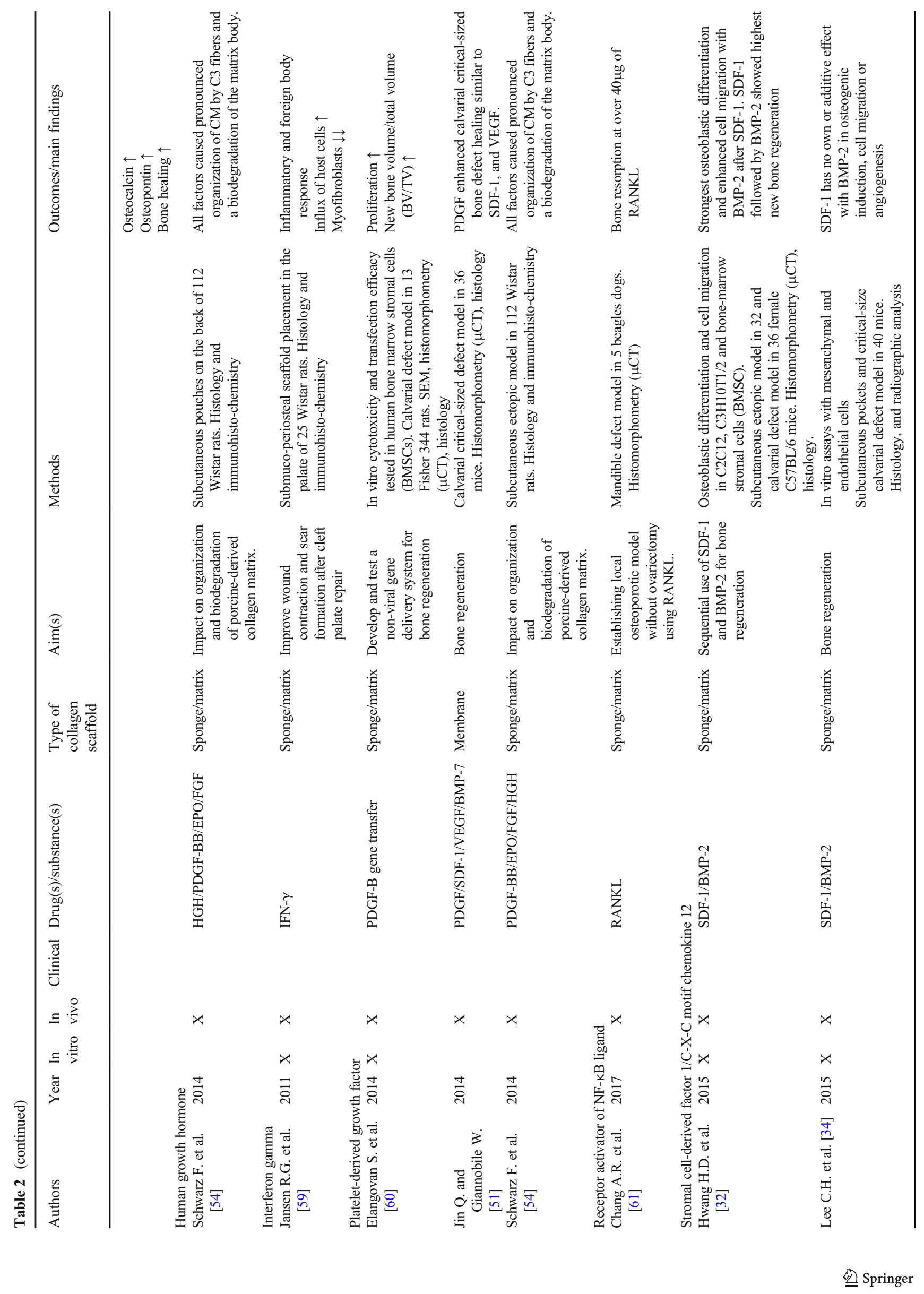




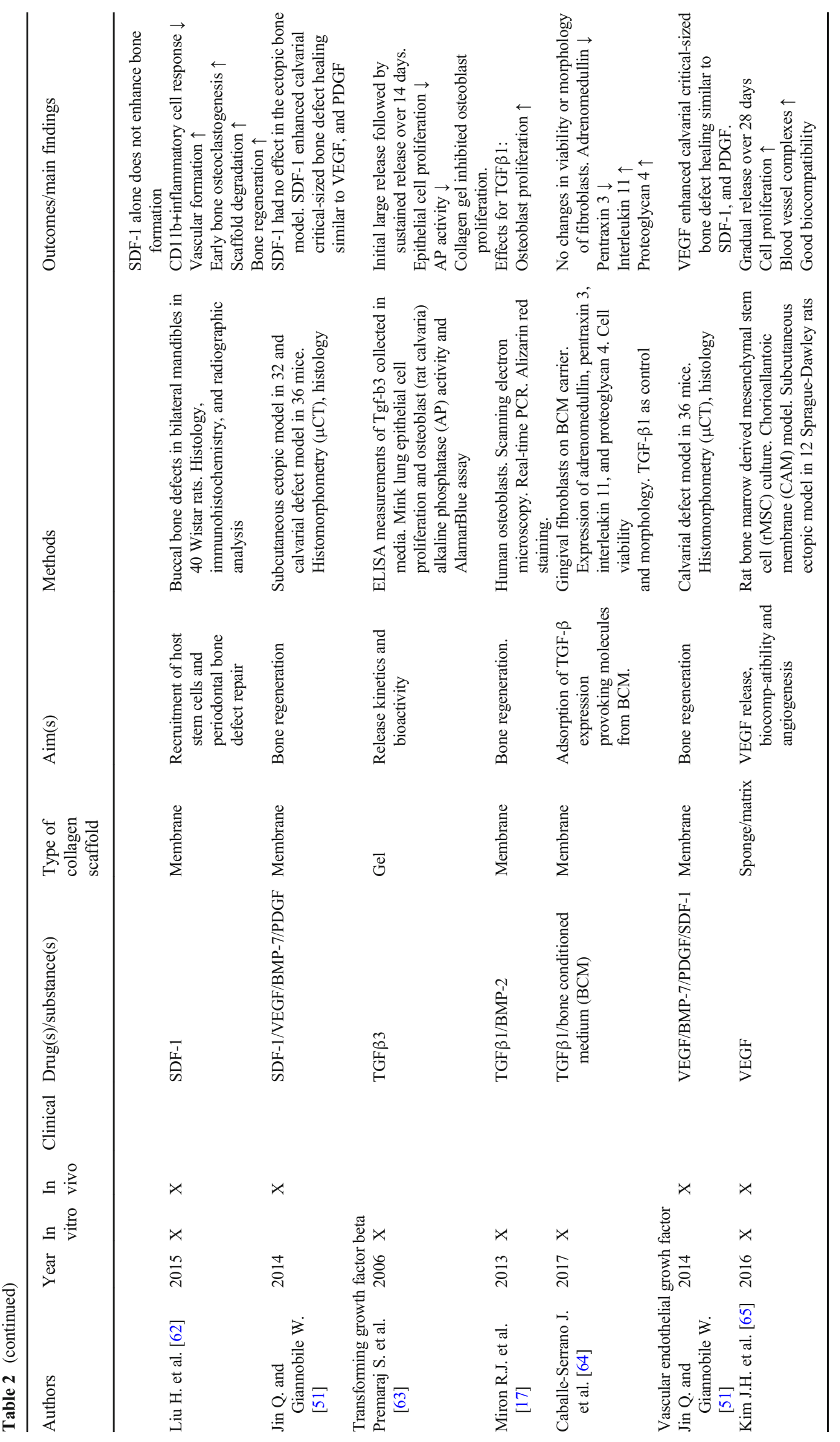




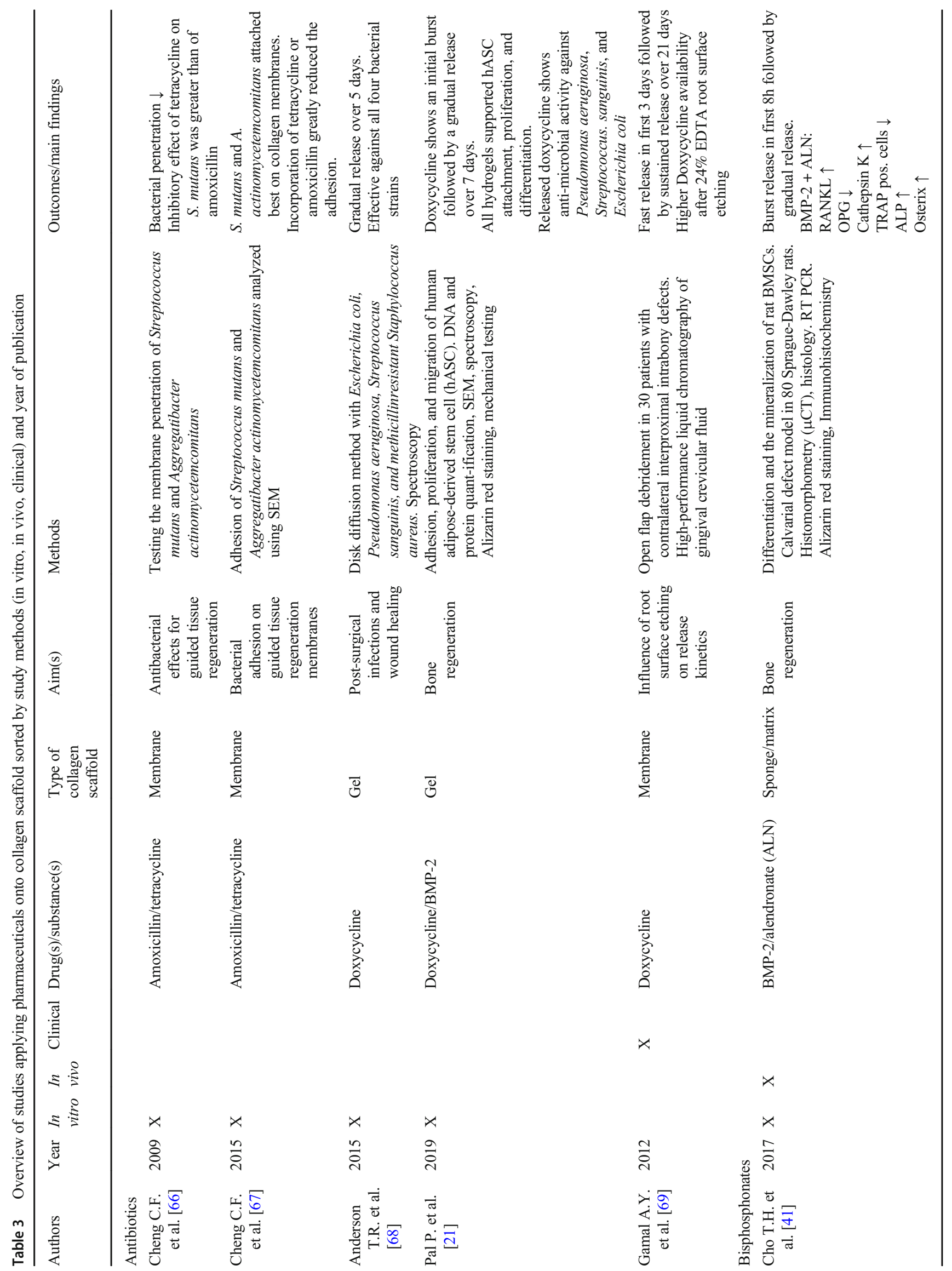




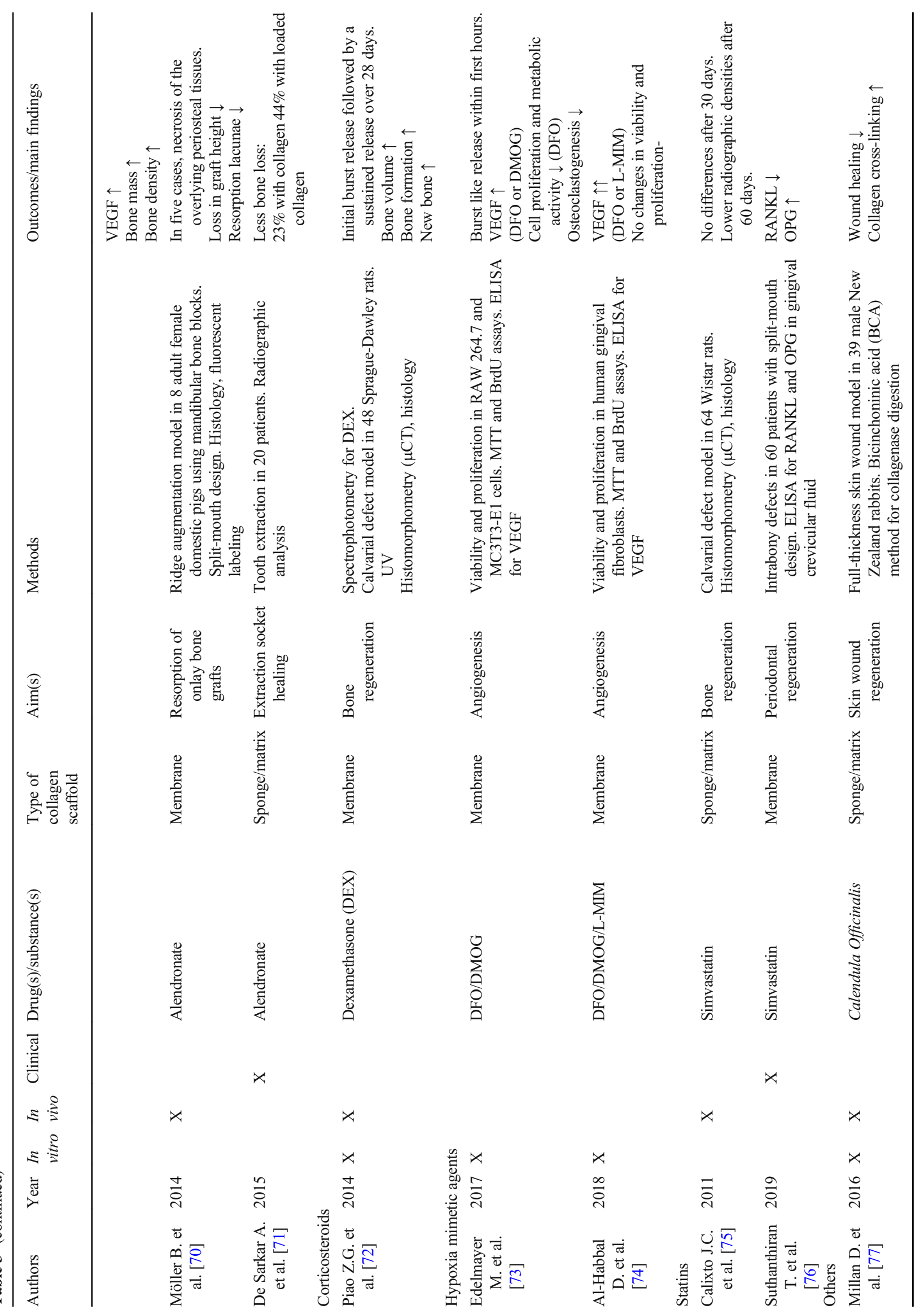




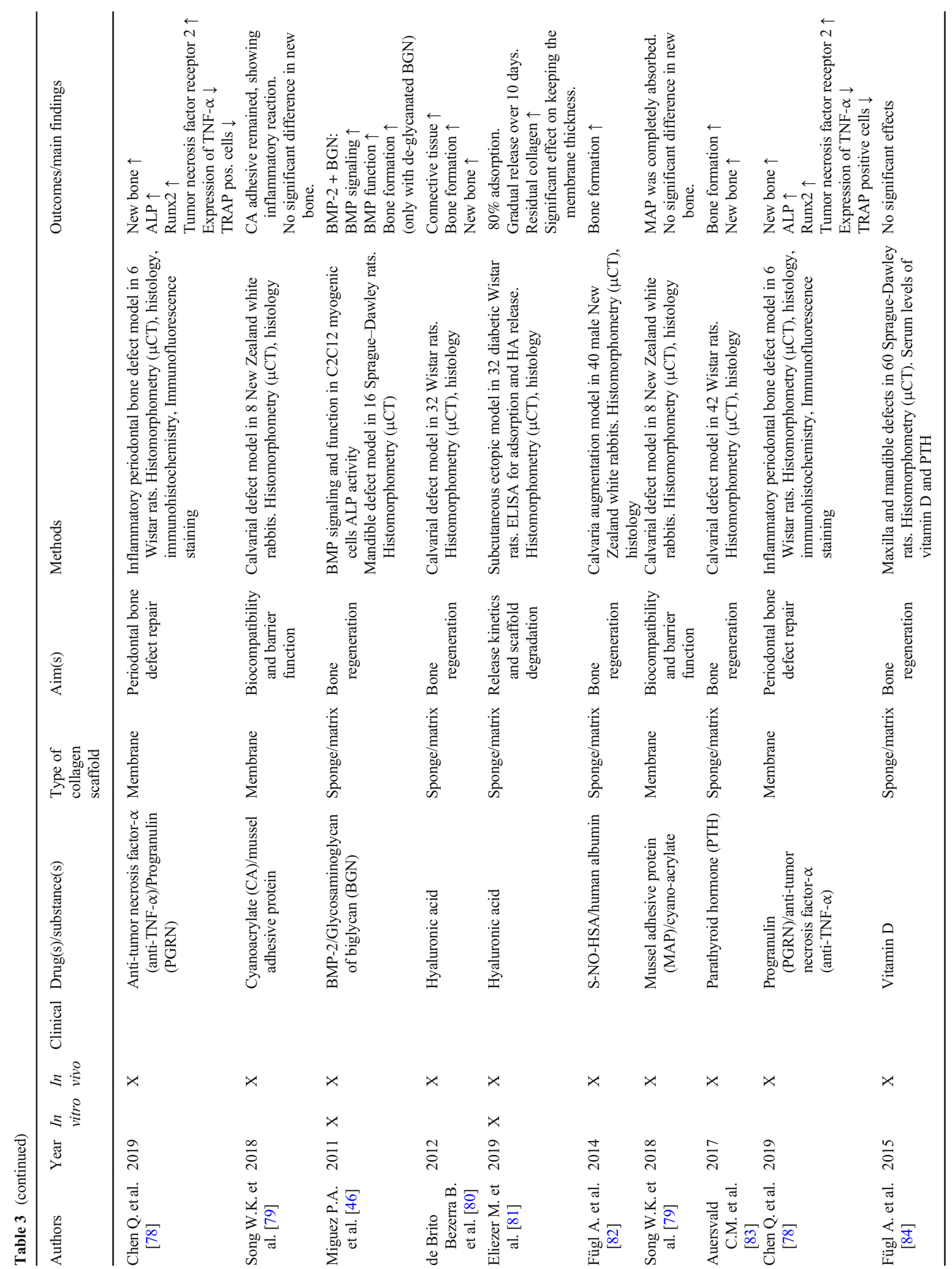




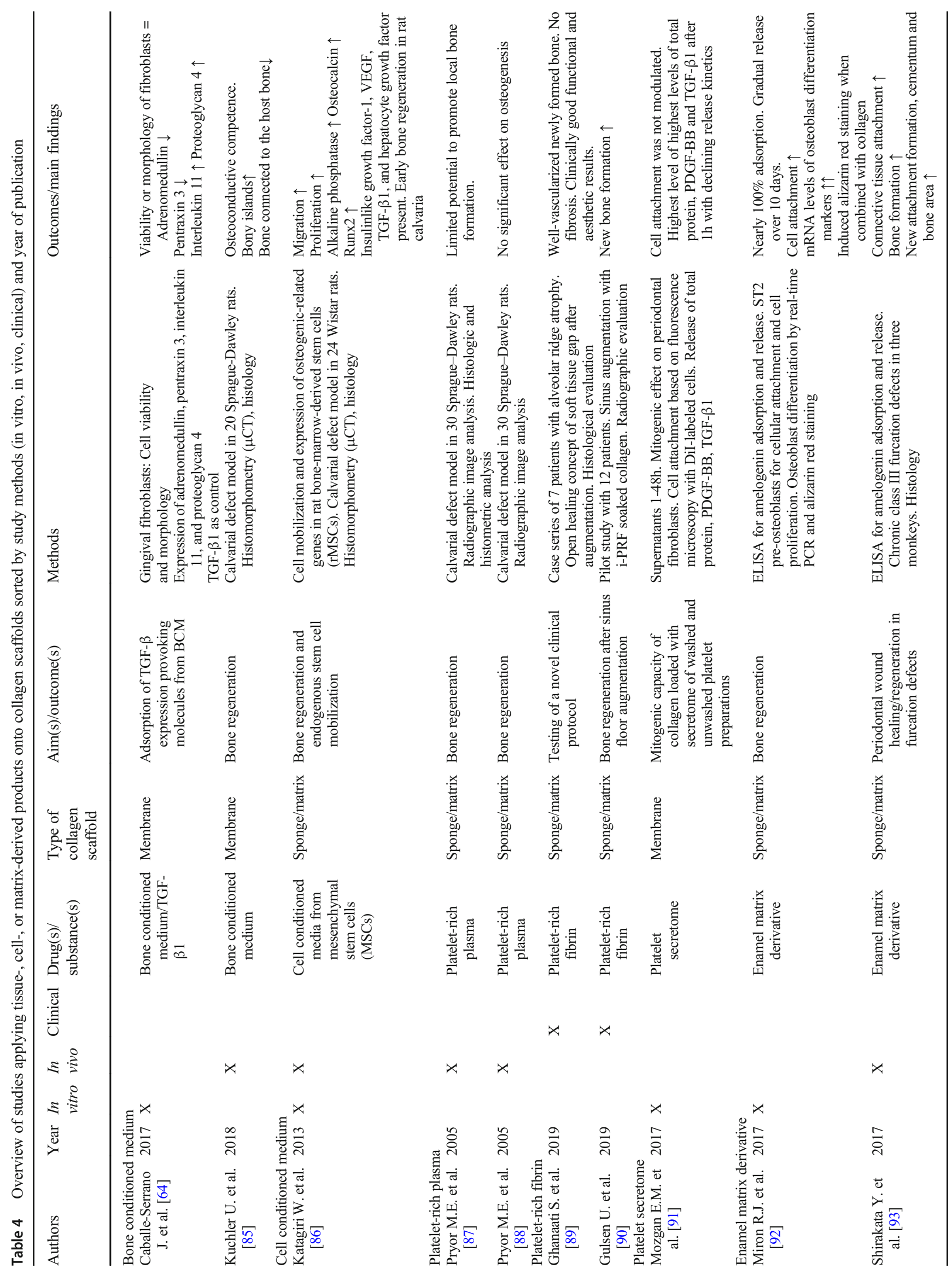


collagen sponges. In $\mathrm{C} 2 \mathrm{C} 12$ myogenic cells, biglycan and BMP-2 loaded collagen scaffolds induced BMP signaling and function at most. When critical-sized mandible defects of 16 Sprague-Dawley rats received loaded scaffolds, bone formation was significantly increased when BMP-2 was combined only with de-glycanated BGN, indicating that the GAG component of BGN functions as a suppressor for the BGNassisted BMP function (Miguez P.A. et al. 2011 [26]). In another study of Jung et al., BMP-2 soaked collagen blocks were implanted in calvarial defects in 60 rats. Groups with loaded scaffolds were compared with blood-filled defects. Bone formation was higher at 8 weeks after invention compared with 2 weeks. Collagen was completely resorbed after 8 weeks. BMP-2 led to a significantly greater augmented area, new bone area, and new bone ratio (Jung J.H. et al. 2011 [27]). In a standardized maxillary sinus model in rabbits, BMP-2 loaded collagen sponges were implanted into left and right maxillary sinuses. After 8 weeks, radiographic analysis showed new bone formation independently of BMP-2. The maximum augmented height did not differ, but maxillary window closure was more advanced in the BMP-2 group (Choi Y. et al. 2012 [28]). For the assessment of vertical GBR purposes, four titanium cylinders were implanted into the external cortical bone of rabbit calvaria. Cylinders were filled with mineralized bone matrix and collagen membranes loaded with BMP-2 or BMP-2 with collagen-binding domain (CBD) were used as coverage. After 6 weeks, new bone trabeculae were observed in the superficial layer when covered with membranes with BMP-2-CBD. Moreover, the average area of newly formed bone was significantly higher in this group compared with BMP-2 or control (Lai C.H. et al. 2013 [29]). Investigating a possible synergistic effect of local BMP-2 and systemic PTH therapy, collagen sponges were loaded with BMP-2 and applied in rat calvarial defects. One group received systemic PTH in addition. BMP-2 loaded collagen scaffolds significantly increased histologic bone formation, whereas PTH did not show a significant additional effect (Stancoven B.W. et al. 2013 [30]). When a GBR procedure was conducted at the buccal side of edentulous maxillary alveolar ridges in dogs, onlay grafts containing bovine hydroxyapatite incorporated with collagen matrix were used and covered by a collagen membrane. In one group, the graft was loaded with BMP-2; in the other group, BMP-2 was loaded onto the collagen membranes. Newly formed bone could be observed in both groups without significant differences. Only the bone-to-residual bone substitute contact ratio was significantly lower in the group where only collagen membranes carried BMP-2 (Chang Y.Y. et al. 2015 [31]). The sequential treatment using SDF-1 before BMP-2 loaded onto collagen scaffold showed an enhanced osteoblastic differentiation, cell migration, and the highest degree of new bone formation in calvarial defects in mice (Hwang H.D. et al. 2015 [32]). When different carrier systems were compared in vivo, collagen sponges, biphasic calcium phosphate blocks and collagenated biphasic calcium phosphate blocks were loaded with BMP-2. Critical-sized calvarial defects in ten rabbits were filled with loaded materials. Histological and histomorphometric analyses were performed at 2 or 8 weeks after surgery. At early stage, new bone formation was significantly less when collagen sponges were used and dimensional stability seemed to be greater in the other groups at both points in time (Jung I.H. et al. 2015 [33]). Lee et al. [34] investigated the effect of the combination of SDF-1 and BMP-2 loading onto collagen scaffolds. BMP-2 induced ectopic and orthotopic bone regeneration, whereas SDF-1 did not have a beneficial effect (Lee C.H. et al. 2015 [34]). Previous studies have revealed that BMP-2 is burst-like released from carriers in the early stage, leading to high peaks of BMP-2 onsite. These high peaks might result in unwanted effects relating to adipose tissue formation, consequently leading to less bone density. Aiming toward a more controlled continuous release, a heparin-conjugated fibrin gel was tested as a carrier of BMP-2. Loaded collagen sponges were used as control. In a critical-sized orthotopic calvarial defect model in rats, solidified gel and collagen sponges which contained BMP at various concentrations were implanted. There was no difference in bone formation and at lower levels of BMP-2 adipose tissue formation was less using loaded gel in comparison with collagen sponges. Findings of the ectopic model using subcutaneous transplantation in 25 immunodeficient mice are not being mentioned in our review as no collagen scaffold was used as carrier material (Lee J.S. et al. 2015 [35]). In 2015, Mostafa et al. (39)[36] compared BMP-2 loaded absorbable collagen sponges with nanofiberbased scaffolds with a collagen backbone to sustain release of BMP-2. In a cleft palate defect model in $30 \mathrm{Wistar}$ rats, BMP2 loaded carriers were placed into the defect and covered with a placental resorbable membrane. In vitro release testing revealed that scaffolds containing a higher content of $2 \%$ of nanofibers released BMP-2 more slowly. After 8 weeks, both BMP-2 treated groups showed higher relative bone filling, whereas the bridging of the bone defect happened to be earlier when using nanofibers (Mostafa N.Z. et al. 2015 [36]). Another study in 2015 investigated a possible additional effect of pulsed electromagnetic fields (PEMF) with BMP-2 treatment. Collagen sponges were soaked in different concentrations of BMP-2 and implanted in the area of rat calvarial defects. PEMF was applied for $8 \mathrm{~h}$ per day over 5 days in one group of animals. Four weeks after surgery, all groups statistically significantly increased bone formation parameters assessed by histology, histomorphometry, and immunohistochemistry irrespective of PEMF. When applying the highest dose of BMP-2 $(10 \mu \mathrm{g})$, no additive effects were observed. Additional PEMF therapy accelerated bone regeneration in groups with lower BMP-2 doses, decreased soft tissue infiltrations into the defect site, and defect spaces were successfully bridged compared with groups without PEMF therapy 
(Yang H.J. et al. 2015 [37]). In a study comparing onlay-type grafted human freeze-dried cortico-cancellous bone blocks (FDBB) and deproteinized bovine bone with collagen (DBBC) loaded with BMP-2 (2.5 $\mu \mathrm{g})$, buffer and BMP-2 loaded collagen sponges acted as control. Scaffolds were placed in rat calvarial defects and 2 or 8 weeks post-surgery, histologic and histomorphometric analyses were performed. At both time points, all BMP-2 groups showed significantly higher new bone area and bone density compared with control. BMP-2 loaded FDBB and DBBC showed significantly higher total augmented area than loaded collagen, but highest bone density could be observed in BMP-2 loaded collagen sponges (Lee J.S. et al. 2016 [38]). Another study in 2016 assessed the effect of limited-dose BMP-2 $(1.5 \mu \mathrm{g})$ loaded biphasic calcium phosphate (BCP) scaffolds on healing of rabbit calvarial bone defects and compared them with BMP2 loaded collagen sponges. The control group received no filling of the defect at all. At 2 or 8 weeks post-operative, both groups showed extensive new bone formation, which was significantly greater after 8 weeks in all groups. In the loaded collagen group, bony collapse was found of the upper defect. New bone formation and the size of the augmented area were significantly greater when using loaded BCP compared with collagen (You H. et al. 2016 [39]). In a study which was aiming to evaluate a novel BCP scaffold, collagen membranes were used as control. Scaffolds were loaded with 20, 50, or $100 \mu \mathrm{g}$ of BMP-2 and applied in cylindrical bone defects which were created bilaterally in the femurs of rats. No unloaded collagen membrane as a negative control was used. BMP-2 was gradually released within 14 days from collagen compared with a rapid release from BCP within 1 day. An increasing concentration of BMP-2 led to higher bone fill irrespective of the carrier system. Loaded collagen membranes at a BMP-2 concentration of $100 \mu \mathrm{g}$ were promoting up to $30 \%$ bone volume over total volume (BV/TV), whereas loaded BCP reached up to $100 \%$. TRAP staining and osteoclast numbers were less in defects receiving BMP-2 loaded collagen scaffolds compared with loaded BCP (Zhang Y. et al. 2016 [40]). BMP-2 combined with alendronate (ALN) led to enhanced osteoblast differentiation and mineralization of mesenchymal stromal cells. Resorption markers showed a higher expression while TRAP positive cells were reduced. In vivo, bone mass and density was increased demonstrating a possible positive effect of ALN together with BMP-2 (Cho T.H. et al. 2017 [41]). In 2018, Durham et al. [42] investigated the effects of collagen sponges loaded with BMP-2 in critical-sized defects in mice. BMP-2 led to greater healing compared with control emanating from the surgical margin. While BMP-2 treatment led to an increase in cell presence within the healing defect there was, however, no regional orientation of craniofacial stem cells or vascularization (Durham E.L. et al. 2018 [42]). To determine the effect on BMP-2 soaked collagen membranes on peri-implant dehiscence effects, implants were placed in five dogs per group where the buccal bone was removed afterwards, resulting in a defect. This defect was filled with bone substitute material and covered with BMP-2 or saline collagen membranes. BMP-2 loaded scaffolds did not improve bone regeneration of this peri-implant bone defects compared with non-soaked membranes (Sun Y.K. et al. 2018 [43]). As the release of growth factors mainly depends on scaffold degradation, another study aimed to improve this condition by using scaffolds in combination with gene transfection using non-viral vectors. Nanohydroxyapatite-collagen scaffolds were loaded with BMP-2-encoding plasmid DNAfunctionalized calcium phosphate nanoparticles, naked plasmid DNA, or BMP-2 solution, and implanted into subcutaneous tissue of the back of rats. Collagen membranes loaded with either of these substances in different concentrations were used as control. The amount and its releasing period of BMP-2, as well as alkaline phosphatase activity were significantly greater in scaffolds loaded with BMP-2-encoding calcium phosphate nanoparticles. Released BMP-2 could be observed on the macrophages or multinuclear giant cells surrounding the scaffold fragments. Tartrate-resistant acid phosphatase (TRAP)- or osteocalcin-positive sites were occurring in all groups and a mineralization area was observed in nanoparticle loaded collagen membranes (Tenkumo T. et al. 2018 [44]). In the first clinical phase II study, which evaluated the safety and efficacy of BMP-2, maxillary sinus floor augmentations were performed in patients who received rhBMP-2 via an absorbable collagen sponge, at concentrations of 0.75 or $1.50 \mathrm{mg} / \mathrm{mL}$. Unloaded bone grafts but not collagen sponges were used as control. CT analysis 4 months after treatment and 6 months post-functional loading revealed similar bone dimension increases but significantly lower bone densities in BMP-2 groups. Bone biopsies at implant placement confirmed normal bone formation (Boyne P.J. et al. 2005 [45]). In another clinical study, five patients with mandibular bone defects have been reconstructed with BMP-2 soaked collagen sponges alone or with bone marrow cells and allogenous cancellous bone chips. No unloaded sponges were used as control. Three cases were showing bone regeneration of the defect site. In two patients the grafts failed but were successfully reconstructed using autogenous bone from the iliac crest (Carter T.G. et al. 2008 [46]). In a case series, seven molarsite implants were placed in six consecutive patients. All sites were augmented with BMP-2 at $1.50 \mathrm{mg} / \mathrm{mL}$ loaded onto a collagen sponge after extraction to enhance bone regeneration prior to implantation. No negative controls were utilized. All sites achieved primary stability at implantation and were functionally loaded. No implants were lost or developed complications during the healing period of 3 to 8 months (Levin B.P. et al. 2012 [47]). Another case series of ten patients implanted collagen sponges loaded with $1.4 \mathrm{~mL}$ BMP-2 into the surgical defect after root resection. Panoramic radiographic and clinical assessments after 3 months revealed sufficient bone 
regeneration. No unloaded scaffolds were used as comparative control (Kumar M.S. et al. 2016 [48]). In a 3-month clinical trial, two BMP-2 delivery systems for alveolar ridge preservation were tested. A total of 32 patients received a collagen sponge soaked with $1.05 \mathrm{mg}$ rhBMP-2 and another 32 patients received $\beta$-tricalcium phosphate and hydroxyapatite scaffold immersed in BMP-2. No unloaded sponges were utilized as control. The loaded scaffolds were placed into the extraction sockets. Dimensional bone changes at 25,50 , and $75 \%$ of extraction socket level and histomorphometric results of bone biopsies before implant placement showed no significant differences (Jo D.W. et al. 2019 [49]).

\section{- Bone morphogenetic protein-6 (BMP-6)}

In critical-sized supra-alveolar periodontal defects in 11 Beagle dogs, collagen sponges were soak-loaded with BMP6 at $0.25,1$, and $2 \mathrm{mg} / \mathrm{mL}$ and implanted into the defects. After 8 weeks, the lowest concentration of BMP- 6 showed the best results compared with control. New bone regeneration and cementum height were significantly enhanced (Chiu H.C. et al. 2013 [50]).

\section{- Bone morphogenetic protein-7 (BMP-7)}

An in vivo study was combining SDF-1 with different growth factors (BMP-7, VEGF, PDGF) to evaluate the regenerative effect in critical-sized calvarial bone defects in mice. BMP-7 $(1 \mu \mathrm{g})$ and SDF-1 $(1 \mu \mathrm{g})$ alone or combined were loaded onto collagen membranes. Maximal bone formation was found in the BMP and the BMP + SDF-1 group at 2 and 4 weeks. After 4 weeks, the defects were almost completely healed. SDF-1 did not show a significant additional effect when combining with BMP-7 (Jin Q. and Giannobile W. 2014 [51]).

\section{- Bone morphogenetic protein-9 (BMP-9)}

Collagen membranes loaded with BMP-9 fully absorbed the substance and slowly released it for up to 10 days. When seeding murine ST2 stromal bone marrow cells onto collagen membranes which were carrying a low $(10 \mathrm{ng} / \mathrm{mL})$ or high $(100 \mathrm{ng} / \mathrm{mL})$ dose of BMP-9, ALP mRNA levels were significantly induced at 3 days and BSP at 14 days. ALP levels were significantly higher (5-fold increase at 3 days and 2-fold increase at 14 days) in groups where the scaffold was loaded with BMP-9 compared with BMP-2. In addition, mRNA levels of collagen1, BSP, and osteocalcin were significantly higher in BMP-9 compared with BMP-2 groups. Effects on cell attachment, proliferation, and on osteoblast differentiation were not significant. Alizarin red staining further showed that BMP-9 induced up to 3-fold more staining in comparison with BMP-2 (Fujioka-Kobayashi M. et al. 2016 [19], Fujioka-
Kobayashi M. et al. 2017 [20]). In a calvarial defect model in rabbits, deproteinized bovine bone mineral (DBBM) was used in combination with a collagen barrier membrane to investigate bone formation using BMP-9. BMP-9 was loaded onto DBBM or the collagen membrane and results were compared with unloaded materials and empty bone defects. Loaded samples promoted significantly higher mineralized tissue volume, new bone height, and new bone area which were evaluated by histomorphometry 8 weeks post-surgery. Multinucleated giant cells could be observed in contact with DBBM surfaces, whereas collagen membranes were not. BMP-9 loaded collagen membranes showed better horizontal wound closure with a faster regeneration of new host bone, suggesting that GBR procedures might benefit more from loaded collagen barrier membranes compared with DBBM (Fujioka-Kobayashi M. et al. 2017 [52], Saulacic N. et al. 2017 [53]).

\section{- Erythropoietin (EPO)}

Due to the known proangiogenic effects of EPO, Schwarz et al. [54] soak-loaded this substance onto collagen sponges. In vitro evaluation of the activity of human gingival fibroblast showed no significant change. When placed in subcutaneous pouches on the back of rats, organization of collagen type III fibers were pronounced and biodegradation of the collagen sponge speeded up after 14 days (Schwarz F. et al. 2014 [54]).

\section{- Fibroblast growth factor $2 / \beta(\mathrm{FGF} 2 / \mathrm{FGF} \beta)$}

D'Mello S. et al. [55] used collagen scaffolds as carrier to deliver polyethylenimine-pDNA nano-sized complexes encoding the FGF2 protein in BMSCs. Recruitment and attachment of BMSCs to scaffolds could be observed using scanning electron microscopy. Complex-loaded scaffolds significantly increased cell proliferation and expression of FGF2 compared with controls (D'Mello S. et al. 2015 [55]). FGF2 loaded onto collagen membranes covering biphasic calcium phosphate bone grafts in calvarial defects in rabbits led to an increase of new bone formation and the amount of residual graft material decreased regardless of different FGF2 concentrations (Lee S.H. et al. 2017 [56]). When FGF2 was loaded onto collagen sponges, in vitro testing of the activity of human gingival fibroblast showed an increase which was not significant. Implanted into subcutaneous pouches on the back of rats, organization of collagen type III fibers was pronounced and biodegradation of the scaffold speeded up after 7 days (Schwarz F. et al. 2014 [54]). In another study, collagen hydrogel fabricated from bovine type I collagen was mixed with FGF2 and injected into sponge-form collagen. Those scaffolds were implanted into class II furcation defects in dogs. At 4 weeks, healing of alveolar bone including cementum-like tissue and periodontal attachment was significantly increased 
(Momose T. et al. 2016 [57]). Collagen sponges impregnated with $5 \mu \mathrm{g}$ of plant-derived rhFGF2 (p-FGF2) protein or E. coli-derived rhFGF2 (e-FGF2) were used to fill a calvarial defect in mice. Both groups, containing differently derived FGF2, enhanced bone healing to higher levels than without FGF2. Proliferation, mineralization, and osteogenic marker expression in MC3T3-E1 cells were also similar, suggesting the usefulness of a plant-based expression system for the production of biologically active rhFGF2 (Poudel S.B. et al. 2019 [58]).

\section{- Human growth hormone (HGH)}

Collagen sponges soak-loaded with $\mathrm{HGH}$ were surgically placed in subcutaneous pouches on the back of rats. Biological activity of human gingival fibroblasts in vitro and organization of collagen type III fibers was insignificantly pronounced. Degradation of the scaffold was accelerated (Schwarz F. et al. 2014 [54]).

\section{- Interferon gamma (IFN- $\gamma)$}

To evaluate the tissue response to IFN- $\gamma$ by investigating a possible decrease in the differentiation of myofibroblasts, collagen scaffolds with or without IFN- $\gamma$ were implanted submucoperiosteally in the palate of rats. Histological and immunohistochemical analyses were performed at 1, 2, 4, 8, and 16 weeks after implantation. IFN- $\gamma$ caused a major numerical reduction in myofibroblasts and a faster influx of host cells (Jansen R.G. et al. 2011 [59]).

\section{- $\quad$ Platelet-derived growth factor (PDGF)}

Non-viral vectors in gene therapy can be a safe and efficient way to deliver growth factors. In a study by Elangovan et al. [60], the aim was to develop such a delivery system for bone regeneration using collagen scaffolds and polyethylenimine (PEI)-plasmid DNA complexes encoding PDGF-B. Low cytotoxicity could be observed and transfection efficacy testing in human BMSCs revealed significant proliferation in vitro. Complex loaded scaffolds showed significantly higher new bone volume to total volume ratio in calvarial defects in rats (Elangovan S. et al. 2014 [60]). An in vivo study was combining SDF-1 with PDGF and other growth factors like BMP-7, VEGF evaluating the effect in critical-sized calvarial bone defects in mice. PDGF $(0.5 \mu \mathrm{g})$ and SDF-1 $(1 \mu \mathrm{g})$ alone or combined were loaded onto collagen membranes. At 2 and 4 weeks, there were no differences in bone mineral content among the groups containing PDGF and SDF-1 alone or in combination, and VEGF. Groups containing BMP-7 significantly showed the maximal bone formation (Jin Q. and Giannobile W. 2014 [51]). Soak-loaded collagen sponges with PDGF-BB showed a significant increase of human gingival fibroblast activity. When implanted in subcutaneous pouches on the back of rats, an ingrowth of collagen type III fibers was observed and biodegradation of the scaffold was significantly faster (Schwarz F. et al. 2014 [54]).

\section{- $\quad$ Receptor activator of NF-KB ligand (RANKL)}

To establish and test a local osteoporotic model without performing an ovariectomy, the mandibles of five beagle dogs were prepared by drilling a hole and implanting a collagen sponge with 20,40 , or $60 \mu \mathrm{g}$ RANKL. The maximum bone density loss of about $40 \%$ could be observed at $40 \mu \mathrm{g}$ RANKL. Dental implants combined with injectable $\beta$ tricalcium phosphate microsphere bone grafts loaded with BMP-2 were placed. The group with the lowest dosage of $5 \mu \mathrm{g}$ BMP-2 showed the highest increase in bone areas and bone to implant contact. These changes in bone regeneration were statistically not significant (Chang A.R. et al. 2017 [61]).

- Stromal cell-derived factor 1 (SDF-1)/C-X-C motif chemokine 12

SDF-1 sequentially followed by BMP-2 soaked onto collagen sponges showed significantly enhanced osteoblastic differentiation and cell migration in vitro. In calvarial defects in mice this sequential treatment showed the highest degree of new bone regeneration. SDF-1 alone did not cause any changes (Hwang H.D. et al. 2015 [32]). A study by Lee et al. investigated the effects of simultaneous SDF-1 and BMP-2 treatment on bone formation. Collagen sponges with or without BMP-2 were loaded with different doses of SDF-1 $(0.1,0.5$, or $1 \mu \mathrm{g})$. SDF-1 had no additive effect on osteoblastic differentiation and cell migration of mesenchymal cells, or capillary tube formation of endothelial cells compared with BMP-2 or SDF-1 alone. Loaded scaffolds were implanted into subcutaneous pockets and critical-sized calvarial defects in mice. SDF-1-only-treated implants did not lead to significant in vivo bone formation and SDF-1 treatment did not improve BMP-2-induced ectopic and orthotopic bone regeneration (Lee C.H. et al. 2015 [34]). To investigate the effects of SDF-1 on bone regeneration in periodontal diseases, collagen membranes loaded with SDF-1 were implanted into established bone defects on the buccal side of bilateral mandibles in rats. The results showed that SDF-1 recruited hostderived mesenchymal stem cells and hematopoietic stem cells to the wound area. CD11b+ inflammatory cell response was significantly reduced. Furthermore, SDF-1 led to an increase in vascular formation, promoted early osteoclastogenesis, accelerated scaffold degradation, and improved the quality and quantity of regenerated bone (Liu H. et al. 2015 [62]). In an in vivo study in mice, SDF-1 was loaded in different dosages onto collagen scaffolds containing BMP-7, VEGF, or PDGF, and implanted into critical-sized calvarial bone defects for 2 
and 4 weeks. Part of this study, where SDF-1 was loaded onto demineralized bone matrix instead of collagen for further in vivo testing, is not being considered in our review. Biopsies were examined using micro-CT $(\mu \mathrm{CT})$ and histology. SDF-1 promoted calvarial critical-sized bone defect healing like VEGF and PDGF, without having significant additional effects when combining it with BMP-7, VEGF, and PDGF (Jin Q. and Giannobile W. 2014 [51]).

\section{- Transforming growth factor beta (TGF- $\beta$ )}

Collagen gels loaded with 100 or $500 \mathrm{ng}$ of TGF- $\beta 3$ demonstrated an initial large release, followed by a sustained release over 14 days which was determined by ELISA measurements. Proliferation of mink lung epithelial cell was not influenced by TGF- $\beta 3$ conditioned media, but alkaline phosphatase activity was decreased. No unloaded control was used (Premaraj et al. 2006 [63]). Collagen membranes soaked in TGF- $\beta 1$ at a concentration of $10 \mathrm{ng} / \mathrm{mL}$ allowed human osteoblasts to adhere and increased osteoblast proliferation at 3 and 5 days post-seeding (Miron R.J. et al. 2013 [17]). In another in vitro study, the authors were investigating if collagen membranes adsorb growth factors from bone conditioned medium. Recombinant human TGF- $\beta 1$ loaded onto collagen membranes served as control, which significantly provoked gene expression of TGF- $\beta$ target genes. No negative controls were utilized (Caballe-Serrano J. et al. in 2017 [64]).

\section{- Vascular endothelial growth factor (VEGF)}

An in vivo study was combining SDF-1 with VEGF and growth factors BMP-7 and PDGF to evaluate the effect in critical-sized calvarial bone defects in mice. VEGF and SDF-1 either alone or combined were loaded onto collagen membranes. At 2 and 4 weeks after surgery, there were no differences in bone mineral content among the groups containing VEGF and SDF-1 alone or in combination, and PDGF. Groups containing BMP-7 showed the maximal bone formation (Jin Q. and Giannobile W. 2014 [51]). Kim J.H. et al. developed a composite scaffold consisting of VEGF loaded onto mesoporous silica nanoparticles, which were then incorporated within a type I collagen sponge. This composite material demonstrated good biocompatibility in a subcutaneous tissue model in rats. VEGF was sustainably released over the test period of 28 days and cell proliferation was increased. Testing with the chick chorioallantoic membrane (CAM) model showed significantly increased numbers of blood vessel complexes compared with scaffolds without VEGF (Kim J.H. et al. 2016 [65]).

\section{Pharmaceuticals}

Pharmaceuticals are fully synthesized drugs which are aiming to influence physiological pathways. In this review, included studies used a wide variety of pharmaceuticals. Those substances were loaded onto collagen scaffolds aiming to influence oral hard and soft tissue regeneration. Some studies also evaluated if certain substances improved properties of the scaffold which indirectly could influence tissue regeneration (Table 3).

\section{Antibiotics}

The use of antibiotics, such as amoxicillin or tetracycline, loaded onto collagen membranes, demonstrated a lower penetration as well as a decreased adhesion of Streptococcus mutans and Aggregatibacter actinomycetemcomitans (Cheng C.F. et al. 2009 [66], Cheng C.F. et al. 2015 [67]). Doxycycline-containing collagen hydrogels showed a gradual time-dependent drug release over 5 days, and indicated efficacy against four bacterial strains (Escherichia coli, Pseudomonas aeruginosa, Streptococcus sanguinis, and methicillin-resistant Staphylococcus aureus) (Anderson T.R. et al. 2015 [68]). Elastin-like polypeptide-collagen hydrogels loaded with doxycycline together with BMP-2 showed an initial burst release within the first $10 \mathrm{~h}$, followed by a gradual release of doxycycline over 7 days, measured by spectrophotometry. Adhesion, proliferation, and migration of human adipose-derived stem cells on hydrogel surfaces was greater and all drug-loaded hydrogels showed bioactivity against P. aeruginosa, S. sanguinis, and E. coli (Pal P. et al. 2019 [21]). In a clinical setting, 30 patients with at least one pair of contralateral interproximal intrabony defects were treated with open flap debridement and placement of doxycycline containing gel in one group. In the other group, exposed root surfaces were etched using 24\% EDTA (EDTA) before gel application. No negative control was carried out. Samples of gingival crevicular fluid of up to 21 days after the intervention were analyzed using high-performance liquid chromatography. In both groups, doxycycline was faster released in the first 3 days, followed by a sustained release over 21 days. After root surface etching, local doxycycline availability of doxycycline was higher (Gamal A.Y. et al. 2012 [69]).

\section{Bisphosphonates}

Alendronate (ALN) combined with BMP-2, loaded onto collagen sponges, enhanced osteoblast differentiation and mineralization of mesenchymal stromal cells in vitro. In a calvarial defect model in 80 rats, bone-forming and bone-resorbing markers showed a higher expression, while TRAP positive cells were reduced. Bone mass and density was also higher, suggesting a positive additive effect of ALN together with BMP-2 (Cho T.H. et al. 2017 [41]). In vivo, alendronate loaded on collagen membranes reduced the surface resorption of onlay bone grafts in a ridge augmentation model in eight pigs. However, in five cases, necrosis of the overlying periosteal 
tissues was observed macroscopically (Möller B. et al. 2014 [70]). In a clinical study with 20 patients, collagen sponges were soaked with $20 \mathrm{mg} / \mathrm{mL}$ alendronate and placed into extraction sockets of incisors and premolars. Collagen sponges alone led to a $22.8 \%$ and loaded scaffolds to a $44.4 \%$ decrease in alveolar ridge resorption (De Sarkar A. et al. 2015 [71]).

\section{Corticosteroids}

Collagen membranes loaded with dexamethasone demonstrated a burst-like initial release, followed by a sustained release over 28 days. In a calvarial defect model in 48 male SpragueDawley rats, bone volume and quality of new bone formation was increased (Piao Z.G. et al. 2015 [72]).

\section{Hypoxia mimetic agents (HMA)}

HMAs such as deferoxamine (DFO), dimethyloxalylglycine (DMOG), or L-mimosine (L-MIM) loaded onto collagen barrier membranes showed a burst-like release in the first hours. In osteoblast- and osteoclast precursor cells (RAW 264.7 and MC3,T3-E1) DFO and DMOG inhibited cell proliferation and metabolic activity. Osteoclastogenesis was significantly reduced by DFO, suggesting a possible positive effect on oral tissue regeneration (Edelmayer M. et al. 2017 [73]). In human gingival fibroblasts, they did not significantly influence cell viability or proliferation (Al-Habbal D. et al. 2018 [74]). In both studies, DFO and DMOG led to an increase in the expression of vascular endothelial growth factor.

\section{Statins}

Simvastatin that was locally administered via collagen sponges at two different concentrations $(0.5 \mathrm{mg} / 50 \mathrm{~mL}$ or $2.2 \mathrm{mg} / 50 \mathrm{~mL}$ ) in a calvarial bone defect model in 64 Wistar rats showed no differences in radiographic densitometry and histometric analyses after 30 days. After 60 days, the group with lower concentrations even showed reduced bone formation, concluding that there was a detrimental effect on bone regeneration (Calixto J.C. et al. 2011 [75]). In a clinical splitmouth setting, collagen membranes loaded with $1.5 \mathrm{mg}$ simvastatin were placed into intrabony defects of 60 patients, while the contralateral site was filled with an unloaded scaffold. Loaded scaffolds significantly increased OPG and decreased RANKL levels in the gingival crevicular fluid, demonstrating a potential role of simvastatin in periodontal regeneration (Suthanthiran T. et al. 2019 [76]).

\section{Others}

- Anti-tumor necrosis factor- $\alpha$ (anti-TNF- $\alpha)$
Collagen membranes loaded with anti-TNF- $\alpha$ were implanted within inflammatory periodontal bone defects of six Wistar rats. The present study showed that anti-TNF- $\alpha$ promotes regeneration of those defects via anti-inflammation, osteoclastogenic inhibition, and osteogenic promotion. However, progranulin had a significantly higher regenerative effect than anti-TNF- $\alpha$ (Chen Q. et al. 2019 [78]).

\section{- Calendula officinalis flower extract}

Collagen scaffolds were loaded with calendula officinalis flower extract and implanted in full-thickness skin wounds in 39 rabbits. Results revealed an inferior wound healing and clinical outcome when compared with the non-loaded control. Collagen cross-linking was increased, leading to a decreased degradation behavior of the scaffolds (Millan D. et al. 2016 [77]).

\section{- Cyanoacrylate}

Evaluating new methods for membrane fixation, a study applied cyanoacrylate on collagen membranes in a rabbit calvarial GBR model. After 8 weeks, little amounts of cyanoacrylate adhesive remained on the collagen membrane, causing an inflammatory reaction. There was no difference in bone regeneration (Song W.K. et al. 2018 [79]).

\section{- Glycosaminoglycan/hyaluronic acid}

In 2011, a study combined glycosaminoglycans (GAG) of biglycan (BGN) together with BMP-2 and collagen scaffolds as a carrier. In $\mathrm{C} 2 \mathrm{C} 12$ myogenic cells, biglycan and BMP-2 combined loaded collagen scaffolds induced BMP signaling and function at most. In vivo, loaded scaffolds were implanted in critical-sized mandibles defects of 16 Sprague-Dawley rats. Bone formation was significantly increased when BMP-2 was combined only with de-glycanated BGN, indicating that the GAG component of BGN functions as a suppressor for the BGN-assisted BMP function (Miguez P.A. et al. 2011 [26]). Collagen sponges that were loaded with $1 \%$ hyaluronic acid gel demonstrated significantly better bone fill of critical-sized calvarial defects in 32 adult Wistar rats (de Brito Bezerra B. et al. 2012 [80]). Collagen membranes soaked with hyaluronic acid showed nearly $80 \%$ adsorption and a gradual release over the observation period of 10 days. When implanted in the scalp pouch of diabetic rats, hyaluronic acid increased the residual collagen content in the diabetic group and delayed membrane degradation significantly (Eliezer M. et al. 2019 [81]).

- S-NO-HSA/human albumin (nitric oxide donor)

S-nitroso human serum albumin (S-NO-HAS) is a donor of nitric oxide which is a mediator involved in bone 
regeneration. Collagen sponges soaked with $100 \mathrm{~mL}$ S-NOHAS $(5 \%, 20 \%)$ demonstrated higher bone formation in a calvarial augmentation model in 40 rabbits compared with the positive control group using human albumin $(5 \%, 20 \%)$. No negative controls were used (Fügl A. et al. 2014 [82]).

\section{- Mussel adhesive protein}

Aiming to improve membrane fixation in GBR procedures, collagen membranes were loaded with mussel adhesive protein and compared with cyanoacrylate. Results suggested excellent biocompatibility of mussel adhesive protein loaded collagen membranes in guided bone regeneration of calvarial defects in rabbits. No difference in bone regeneration was found (Song W.K. et al. 2018 [79]).

\section{- Parathyroid hormone}

Collagen sponges soaked with parathyroid hormone significantly exhibited higher bone formation and new bone after 15 to 60 days of healing of calvarial defects in 42 male rats (Auersvald et al 2017 ${ }^{63}$ ).

\section{- Progranulin}

Recombinant human progranulin loaded onto collagen membranes were implanted within inflammatory periodontal bone defects of six Wistar rats. After 2 weeks, antiinflammatory effects as well as inhibition of osteoclastogenesis and promotion of osteogenesis were seen (Chen Q. et al. 2019 [78]).

\section{- Vitamin D}

Topical application of calcitriol loaded onto collagen sponges did not promote bone regeneration in single maxillary or mandibular defects in vitamin D deficient rats (Fügl et al $\left.2015^{47}\right)$.

\section{Tissue-, cell-, and matrix-derived products}

\section{Bone conditioned medium (BCM)}

In vitro, Caballe-Serrano et al. [64] generated bone conditioned medium (BCM) by placing demineralized harvested bone chips in cell culture medium. Aqueous soaked collagen membranes were placed in BCM to see if these scaffolds adsorb grow factors activating TGF- $\beta$ signaling. Collagen membranes with $\mathrm{BCM}$ decreased the expression of adrenomedullin and pentraxin 3 and increased the expression of interleukin 11 and proteoglycan 4 in gingival fibroblasts. $\mathrm{BCM}$ did not influence the viability or morphology of the fibroblasts (Caballe-Serrano J. et al. in 2017 [64]). In a calvarial defect model in rats, collagen membranes were soaked in bone conditioned medium or culture medium as control and implanted in the defect site. No unloaded control was used. The control group showed significantly more bone than the BCM group. Scanning electron microscopy and histology showed that BCM might shift bone formation toward the formation of bony islands rather than new bone connected to the host bone (Kuchler U. et al. 2018 [85]).

\section{Cell conditioned medium (CCM)}

Cultured conditioned media from human bone marrowderived mesenchymal stem cells (MSC-CM) was collected to investigate its influence on endogenous stem cell mobilization and bone regeneration. Insulin-like growth factor-1, vascular endothelial growth factor, transforming growth factor- $\beta 1$, and hepatocyte growth factor were present in the MSC-CM. When MSC-CM was cultured with rat bone marrow-derived stem cells, migration, proliferation, and expression of alkaline phosphatase, osteocalcin, and Runx2 was increased. Collagen sponges soaked with MSC-CM were grafted into rat calvarial bone defects and showed early bone regeneration (Katagiri W. et al. 2013 [86]).

\section{Platelet-rich plasma (PRP)}

PRP preparations from donor rats were soak-loaded on absorbable collagen sponges and surgically implanted into contralateral critical-sized calvaria osteotomies in 18 rats. Histologic and histometric analysis after 4 or 8 weeks showed that bone formation was highly variable in PRP sites as well as in controls. Radiographic analysis did not show significant differences to the control group. Conclusively, PRP preparation did not enhance bone regeneration in vivo (Pryor M.E. et al. $2005[87,88])$.

\section{Platelet-rich fibrin (PRF)}

In a clinical case series of seven patients with alveolar ridge atrophy of different etiologies, a novel augmentation protocol using a combination of xenogeneic bone substitutes covered with PRF loaded onto collagen carriers was carried out. No autologous bone transplantation or periosteum splitting was performed. The gap between the flap margins was bridged using the collagen matrix loaded with liquid PRF. No unloaded collagen matrices were used as control. The whole augmented site was finally covered by either a PTFE-based membrane or sterile latex. After 4 to 8 months, open healing resulted in newly formed soft tissue without any signs of scar formation or fibrosis. Biopsies during implant insertion histologically showed well-vascularized newly formed bone that incorporated the BSM granules (Ghanaati S et al. 2019 [89]). A retrospective clinical pilot study with 12 patients utilized 
injectable platelet-rich fibrin (iPRF) preparations loaded onto collagen sponges as a graft for sinus augmentation. No negative controls were carried out. Minimum and maximum residual subantral bone heights were 2.0 and $9.8 \mathrm{~mm}$. After 6 months, panoramic radiographic measurements showed significant new bone formation at all sites. Implants of 10.0 or $11.5 \mathrm{~mm}$ length were placed successfully (Gülsen U. et al. 2019 [90]).

\section{Platelet secretome (PSEC)}

In a study by Mozgan E.M. et al. [91], secretome of washed platelets (washed PSEC) and secretome of unwashed platelet preparations (unwashed PSEC) were lyophilized onto CBM. Supernatants were collected by adding and replacing medium after 1 to $48 \mathrm{~h}$. Mitogenic response of human periodontal fibroblasts was induced by the supernatants and showed the highest levels of total protein, TGF $\beta 1$, and PDGF-BB in the first hour. These effects decreased rapidly in subsequent time points resulting in continuously declining release kinetics (Mozgan E.M. et al. 2017 [91]).

\section{Enamel matrix derivative (EMD)}

EMD demonstrated efficient adsorption properties on absorbable collagen sponges. Nearly $100 \%$ of the amelogenin proteins could be found after loading. Release kinetics showed a gradual release for up to 10 days. EMD significantly induced a 1.5-fold increase in cell attachment and resulted in a 2-6-fold increase in mRNA levels of runt-related transcription factor 2 (Runx2), collagen1a2, alkaline phosphatase, and bone sialoprotein. Alizarin red staining was pronounced when combined with ACS (Miron R.J. et al. 2017 [92]). In vivo, two different EMD carriers (Emdogain $\AA / O s t e o g a i n \AA)$ soaked on separate absorbable collagen sponges (ACS) were applied upon periodontal wound regeneration in chronic class III furcation defects in monkeys. A significantly higher amount of total adsorbed amelogenin was found for ACS-loadedOsteogain ${ }^{\circledR}$ when compared with Emdogain ${ }^{\circledR}$. Combined with open flap debridement (OFD), both substances resulted in higher amounts of connective tissue attachment and bone formation, compared with treatment with OFD + ACS and OFD alone. Osteogain ${ }^{\circledR}$ showed higher new attachment formation, cementum, and new bone area (Shirakata Y. et al. 2017 [93]).

\section{Discussion}

Enhancing regenerative properties of scaffolds for oral tissue engineering remains an important study objective. The timeline of the past 15 years of scientific literature in this field (Fig. 1) together with the high number of 77 included journal articles and the large variety of 36 different substances which have been used, demonstrate the importance of this topic (Tables 2,3, and 4). One of the reasons might be the common use of collagen biomaterials in oral and maxillofacial surgery as well as in periodontal treatment. GBR or GTR procedures often require collagen scaffolds as tissue substitute or to cover bone grafts. Biocompatibility, impenetrability for epithelial cells and bacteria, degradation behavior and physical or architectural properties which allow mechanical stability are important elements for scaffolds. Also, adequate adsorption of loaded drugs and their diffusion as well as controlled release, are factors which are indispensable [95]. Improving regenerative capabilities of these scaffolds by additionally adding regenerative substances might seem to be the next logical step. Today, the clinical use of drug loaded scaffolds in oral and maxillofacial surgery is still limited as only few substances are clinically approved and therefore available.

\section{Literature search and excluded studies}

Out of 259 unique search results of all three database findings, 182 publications were excluded. The major reason was that in 72 of these studies, other biomaterial carriers than collagen were used in their investigations. These studies were matching the inclusion criteria and were therefore part of the initial findings. This might be explained due to the often-used method of assessing the effect of other biomaterials on the gene regulation of collagen, the collagen synthesis or the secretion level. In 28 studies, loading of the collagen scaffold did not take place. In these cases, bone substitute materials were loaded and unloaded collagen membranes were only used to cover the grafted site. As previously stated, only studies utilizing collagen as carrier material were taken into consideration for being included in this review. Since cell-based therapies are not approved for the clinical use for oral applications yet, the authors chose not to include this alternative approach, leading to 22 studies which had to be excluded.

\section{Types, adsorption, and release kinetics of collagen scaffolds}

Looking at the types of collagen scaffolds which were utilized as carrier materials, sponges or matrices were used in 50, membranes in 23 , and gels in only 4 studies. The selection of the scaffold type might often have depended on the planned clinical application. In a clinical setting, sponges or matrices are usually used to fill soft or hard tissue defects, while membranes are used as a cover and gels for defects which require a more flowable consistency of the carrier. In our review, we found that nine out of ten clinical studies used sponges or matrices, while the remaining one was using membranes. Scaffold selection in in vitro testing was evenly distributed using sponges or matrices in 15 and membranes in 13 
publications. In vivo experiments more often used sponges or matrices $(n=37)$ than membranes $(n=15)$. Gels were only used for in vitro testing (Tables 2-4). Adsorption behavior was not assessed in gels. In membranes, mussel adhesive protein was completely adsorbed and cyanoacrylate adhesive remained, showing an inflammatory reaction [79]. Sponges fully absorbed BMP-2 and BMP-9 [20], whereas hyaluronic acid was nearly $80 \%$ adsorbed [81] and amelogenin proteins were adsorbed by almost $100 \%$ [92]. Out of all 77 included articles, 18 studies investigated release properties of different substances from collagen carriers $[18,20,21,35,36,40,41$, $44,63,65,68,69,72-74,81,92]$. Release kinetics of sponges or matrices showed an initial burst-like release phase of BMP2 and BMP-9 within the first 8 to $24 \mathrm{~h}$ and subsequently a slower continuous phase from deeper layers over 10 days [20, 41]. Hyaluronic acid and amelogenin were gradually released over 10 days and VEGF over 28 days [65, 81, 92]. Collagen membranes released BMP-2 fast in the first $24 \mathrm{~h}$, followed by a gradual release over 28 days [40,44]. Doxycycline was faster released in the first 3 days, followed by 21 days of sustained release. Dexamethasone, DMOG, and DFO were bust-like released from membranes in the first hours and while dexamethasone was continuously released for 28 days, DMOG was not detectable after $24 \mathrm{~h}$ and DFO rapidly declined after a period of $48 \mathrm{~h}$ [72-74]. PSEC burst-like released in the first hour, then declining over the 48-h observation period [91]. Collagen gels were tested for their release kinetics of BMP-2, TGF $\beta 3$, and doxycycline. One study demonstrated a burst-like release of BMP-2, followed by a gradual release over 28 days [18]. Another study showed a gradual release from the beginning for the period of 7 days [21]. Also, doxycycline release kinetics were different in three studies. While it was gradually released in one study for 5 days [68], another study demonstrated a burst-like release in the first hours, followed by a gradual release over 7 days [21]. In a clinical setting, doxycycline was faster released from collagen membranes within the first 3 days followed by a sustained release over 21 days [69]. The release of TGF $\beta 3$ from gels revealed to be characterized by an initial burst-like phase with a delayed release for up to 14 days [63]. Release periods were always the maximum time of observation, while the release was never complete at that time point unless otherwise stated. In vivo, collagen sponges were completely resorbed after 8 weeks [27]. Studies trying to establish a slower and more controlled release were successful by using nanofibers or gene transfection applying non-viral vectors, whereas heparin-conjugated fibrin gel did not improve release kinetics [35, 36, 44].

\section{Biological medical products}

Growth and differentiation factors, especially bone morphogenetic proteins, were by far the most frequently applied substances. BMPs belong to the transforming-growth-factor- $\beta$ superfamily and comprise 13 BMP family members according to the current nomenclature. BMP-2, BMP-4, BMP-6, BMP7, and BMP-9 play an important role in ossification [96], while BMP-2, BMP-6, and BMP-9 are most potent in inducing differentiation of stem cells into osteoblasts [97]. Recombinant BMP-2 and BMP-7 are officially approved and available for clinical use. Although there are specific bone-related indications for treatment, up to $85 \%$ of usage is off-label and also the costs are very high [98]. Current clinical applications in oral and maxillofacial surgery are tooth extraction socket healing $[99,100]$, mandibular bone reconstruction $[46,101,102]$, alveolar reconstruction for cleft repair [103, $104]$, or maxillary sinus augmentation procedures $[105,106]$. In this review, studies were investigating the effects of BMP2, BMP-6, BMP-7 and BMP-9. All types of bone morphogenetic proteins increased osteoblast differentiation markers and improved hard and soft tissue healing in general and when compared with other substances in vivo $[17,18,22,24,25$, $27,28,33,35,36,39,40,42-44]$. Previous studies have shown that adverse effects can occur, especially if the local concentrations of BMPs are too high. Side effects are ranging from inflammatory complications to osteoclast activation, induction of adipogenesis and bone cyst formation and wound complications [107-110]. In a clinical study, BMP-2 soaked collagen sponges in some cases supported the regeneration of mandibular bone defects [46]. Additional systemic PTH therapy or SDF-1 in combination with BMP-2 did not have any significant effects on tissue regeneration [30, 51]. The application of pulsed electromagnetic fields to stimulate bone regeneration resulted in increased bone volume and density and improved the microarchitecture of the regenerated bone in groups with lower concentrations of BMP-2 $(2.5$ and $5 \mu \mathrm{g})$, suggesting its ability to reduce BMP-2 doses to avoid adverse effects of high concentrations. Schwartz et al. previously reported that PEMF enhanced the osteoinductive effects of BMP-2 on mesenchymal stem cells, which might be an interesting aspect to investigate in further studies [111]. In supraalveolar periodontal defects in dogs, BMP-6 at the lowest applied concentration loaded onto collagen sponges showed the best results in bone regeneration and cementum height [50]. Previous studies have shown that the effects of BMP-9 on ossification are the strongest, followed by BMP-2 and BMP-7 [96]. In a study evaluating the additional effect of SDF-1 on local BMP-7 treatment utilizing collagen membranes, BMP-7 increased maximal bone formation without beneficial effects of SDF-1 [51]. Comparing BMP-9 to BMP-2 loaded collagen scaffolds, BMP-9 showed similar release kinetics but induced significantly greater ALP, collagen1 mRNA, BSP, and osteocalcin levels in murine ST2 stromal bone marrow cells. Cell attachment, proliferation, and osteoblast differentiation did not differ, but alizarin red staining was three times higher compared with BMP-2 $[19,20]$. In vivo, BMP-9 loaded onto collagen membranes enhanced 
bone regeneration parameters and showed faster horizontal wound closure $[52,53]$. When erythropoietin, which is well known for its proangiogenic effect, or human growth hormone or fibroblast growth factor 2 were loaded onto collagen sponges and implanted in subcutaneous pouches on the back of rats, scaffold degradation was faster and organization of collagen fibers was pronounced [54]. Collagen membranes loaded with FGF2, covering biphasic calcium phosphate bone grafts in vivo, led to an increase in new bone formation and decreased graft residuals [56]. Aiming to develop a new way of delivery, plasmid DNA complexes encoding for FGF2 carried by collagen scaffolds increased proliferation and FGF2 expression in BMSCs [55]. In a periodontal model, FGF2 mixed with collagen hydrogel and injected into furcation defects of dogs, bone healing and periodontal attachment were significantly increased [57]. Submucoperiosteally in rat palates IFN- $\gamma$ loaded collagen scaffolds reduced the number of myofibroblasts and supported the influx of host cells [59]. PDGF soak-loaded on collagen sponges increase human gingival fibroblast activity and scaffold degradation [54]. In a rat calvarial defect model, PDGF increased bone mineral content similar to SDF-1 or VEGF alone [51]. Evaluating an efficient way to deliver growth factors, plasmid DNA complexes loaded onto collagen scaffolds, encoding PDGF, were shown to be effective and significantly enhanced new bone volume to total volume ratio in vivo [60]. Aiming to establish a local osteoporotic model without ovariectomy, collagen sponges loaded with RANKL were successfully used to cause bone loss [61]. SDF-1 is essential for BMP-2 induced osteogenic differentiation. In vivo, SDF-1 alone had no effect in a study but increased bone mineral content in vivo comparable with VEGF or PDGF alone in another study [51]. The sequential treatment of SDF-1 after BMP-2 increased bone regeneration and enhanced differentiation and migration of osteoblasts in vitro [32]. In combination with BMP-7, SDF-1 showed no additional effect [51]. In a periodontal defect model in rats, SDF-1 increased migration of MSCs, reduced inflammation, accelerated scaffold degradation, and improved bone regeneration [62]. TGF- $\beta 1$ soaked collagen membranes increased human osteoblast adhesion and proliferation [17]. VEGF is a potent inducer of angiogenesis, which is a key factor to repair damaged tissue. Loaded onto collagen membranes, VEGF significantly increased bone mineral content after 2 and 4 weeks in vivo, comparable with SDF-1 and PDGF [51].

\section{Pharmaceuticals}

In this particular subgroup, 16 different substances have been used in 24 studies. Evaluating the effect of antibiotics loaded onto collagen membranes and hydrogels, findings of the included studies demonstrated a lower penetration and decreased adhesion of different types of bacteria [66-69]. Bisphosphonate (alendronate) loaded collagen scaffolds enhanced osteoblast differentiation and mineralization of MSCs in vitro [41] and significantly reduced bone loss of the alveolar ridge after tooth extraction clinically [71]. While alendronate also reduced surface resorptions of onlay bone grafts in vivo, in five of eight pigs, necrosis of the overlying periosteal tissues could be observed, suggesting that high local concentrations might be disadvantageous [70]. Corticosteroids, glycosaminoglycan, or hyaluronic acid, human serum albumin, parathyroid hormone, and progranulin enhanced bone regeneration in vivo in rat or rabbit calvarial defects $[26,72,80,82]$. Hypoxia mimetic agents showed diverse effects on osteoblast and osteoclast precursor cells as well as VEGF expression in vitro [73]. Statins and extracts of the calendula officinalis flower loaded on collagen sponges or gels, respectively, had adverse effects on wound healing in bone defect models in vivo [75, 77]. However, a clinical study using simvastatin loaded membranes for periodontal regeneration showed a decrease in RANKL and an increase in OPG in gingival crevicular fluid, which might demonstrate a potential role of simvastatin in periodontal regeneration [76]. As collagen membranes often need to be fixated as part of GTR or GBR procedures, suturing and screw or tag placement might be necessary, which might be complicating the procedure. Also, additional interventions are needed as sutures and especially screws or tags might need to be removed. Application of resorbable surgical adhesives appear to be more convenient as cyanoacrylate has been used for decades to replace sutures, and also closures of sinus membrane perforations during sinus lift procedures [112] or gluing autologous bone grafts onto recipient beds after demineralization seem to be successful [113]. Aiming to use surgical adhesives instead, cyanoacrylate or mussel adhesive proteins loaded onto collagen membranes demonstrated that small remains of cyanoacrylate were still existent after 8 weeks, causing inflammation, while mussel adhesive protein showed excellent biocompatibility [79]. Due to previous studies, showing that cyanoacrylate is not fully adsorbed and causing adverse reactions $[114,115]$, mussel adhesive protein might have its advantages and therefore calls for further investigations.

\section{Tissue-, cell-, and matrix-derived products}

In 10 out of 77 included studies, investigators applied products derived from tissue, cells, or matrices. Bone conditioned medium loaded on collagen membranes was influencing TGF-b target genes but did not improve the formation of new bone in vivo $[64,85]$. Conditioned medium of human bone marrow-derived mesenchymal stem cells increased activity, migration, and proliferation of rat bone-marrow-derived stem cells [86]. Collagen scaffolds were also successfully used as carriers of platelet-rich plasma, proved to preserve essential growth factors [116], and the use of platelet secretome induced mitogenic response and the expression of 
growth factors in human periodontal fibroblasts [91]. Enamel matrix derivate demonstrated a positive effect in cell attachment, osteoblast differentiation, and proliferation [92]. In vivo, bone formation and connective tissue formation were increased when evaluating the effect of EMD on periodontal regeneration [93]. Platelet concentrates or "platelet-rich plasma" (PRP) were already introduced in the 1990s, aiming to promote local healing at surgical sites [117]. PRP requires the addition of anticoagulants during blood collection while PRF is obtained by centrifugation without anticoagulants and is therefore completely autologous. This fibrin matrix contains platelets and leukocytes as well as a variety of growth factors [118]. In a clinical case series, a novel augmentation protocol for alveolar ridge atrophy, using xenogeneic bone substitutes covered with PRF loaded onto collagen carriers, was performed. Results showed newly formed soft tissue without any signs of scar formation or fibrosis and well-vascularized newly formed bone [89]. A retrospective clinical pilot study aimed to use PRF without any hard tissue substitute for sinus floor augmentation. Injectable platelet-rich fibrin (iPRF) was prepared and loaded onto collagen sponges as a graft which were then implanted. Panoramic radiographic measurements showed significant new bone formation [90]. Follow-up data or three-dimensional measurements were missing and would be recommended for future studies.

\section{Limitations}

In our review, included literature most often conducted in vivo $(55 \%)$ and in vitro (34\%) experiments, whereas only $11 \%$ conducted clinical testing with patients. The evidence level of in vitro and animal experiments is regarded to be low, even though these studies are forming the basis for studies in humans. New substances and methods need to be evaluated in an in vitro and in vivo setting, before employing design and results from these studies. Out of ten clinical studies, four were case series with five to ten patients [46-48, 89], one was a pilot study with 12 patients [90], and five were clinical trials with 20 to 64 patients [45, 49, 69, 71, 76]. Contrary to our research question, we did not exclude studies without unloaded controls. The reason was that we aimed to provide a wider scope and to discuss articles which primarily focused on release properties without using negative controls. Articles which did not use negative controls were distinctly pointed out in our review. Only two out of ten clinical trials - which applied statins or bisphosphonates - used unloaded collagen scaffolds as control [71, 76], whereas the other eight studies in humans did not $[45-49,69,89,90]$. The absence of negative controls leads to results which might show the feasibility and dose-dependent changes of certain methods but do not allow any further conclusions. Overall, the evidence level of included publications was low and the risk of bias was high. One reason for the low number of clinical studies might be the fact that specific clinical applications require other bone substitute materials which have not been included in this review. Another reason might be the low number of clinically approved substances and therefore a lot of studies still focus on pre-clinical testing before clinical tests may follow. This review shows that clinically available BMP-2 was more often investigated. BMP-2 has been investigated in 33 studies, while other growth factors or substances which demonstrated positive effects on tissue regeneration were evaluated in only one to five studies. Today, the only stem cell-based treatment that is routinely reviewed and approved is hematopoietic stem cell transplantation. Cell-based therapy approaches might be a paradigm shift that may provide alternative therapeutic solutions for several diseases. Currently, many preclinical and clinical studies are conducted to approve cell-based therapies for diverse applications. As this approach is still under debate and the use in oral medicine is still not approved, we did not include studies which were focusing on these substances. While there are other bone substitute materials which are used for oral tissue regenerative applications, we focused on collagen scaffolds as they are commonly used and have been established in many applications as the gold standard. Another commonly used biomaterial for oral tissue engineering and regeneration is deproteinized bovine bone mineral alone or in combination with collagen. Evaluation of all available biomaterials in our review would have gone beyond the scope. A further review might be needed to address this aspect on its own.

Our research question primarily focused on the effects of substance loaded collagen scaffolds on oral tissue regeneration compared with unloaded scaffolds. Nevertheless, we did not exclude studies which were not using unloaded collagen scaffolds as control or even used loaded collagen scaffolds as a control for other loaded biomaterials. This way, we were able to include five additional journal articles which investigated release properties of carriers which did not use an unloaded scaffold $[63,68,73,74,91]$. The use of substance loaded bone substitute materials for applications in guided bone or tissue regeneration is still in an early phase of clinical use und needs further trials. A wide range of different bone substitute materials are widely used in clinical applications, whereas the availability of drug-loaded scaffolds is still low. Our review of the past 15 years of scientific experiments applying loaded collagen scaffolds includes 77 publications. These studies investigated 36 different substances. These facts might indicate that widespread investigations are aiming to find candidates to improve the regenerative potential of collagen scaffolds. Testing of all substances were performed in a pre-clinical setting (in vitro, in vivo), resulting in a low evidence level. Only BMP-2, doxycycline, alendronate, simvastatin, and platelet-rich fibrin were tested in humans, while the study design was qualitatively poor and had a high risk of bias. Overall, BMP-2 was most frequently investigated and low 
doses of BMP-2 showed positive effects on oral regeneration in all studies. BMP-9 might have more pronounced effects compared with BMP-2, even at lower concentrations. FGF2 was tested in five studies, demonstrating an increase in bone and periodontal healing. Collagen scaffolds loaded with antibiotics improved the scaffold's anti-microbial activity and even reduced the penetrability for bacteria. Other biological medical products, pharmaceuticals, and tissue-, cell-, and matrix-derived products showed positive or diverse effects on hard tissue and soft tissue regeneration. Because of the low number of studies for each of these substances, results might not be reliable and need to be further investigated. Collagen scaffolds of any type have proven, in any of the included experiments, that they are functional and clinically acceptable carrier materials for any kind of substance without having any negative effect by itself.

\section{Conclusion}

Collagen scaffolds of any type have proven to be capable carriers for all 36 substances which were utilized in the 77 included publications. Adsorption and release kinetics of all assessed substances showed clinically favorable results. These properties were also influenced to optimize the burst-like initial release and prolong the release. Biological medical products were by far investigated most often. Especially BMP-2 was investigated most frequently and showed positive effects on oral regeneration in all 33 studies where it was applied on different types of collagen scaffolds. BMP-9 showed more pronounced effects compared with BMP-2, even at lower concentrations. FGF2 demonstrated an increase in bone and periodontal healing. Pharmaceuticals were used in 24 studies to be loaded onto collagen carriers. Collagen scaffolds loaded with antibiotics improved the scaffold's anti-microbial activity and even reduced the penetrability for bacteria. Hyaluronic acid might prolong collagen membrane stability. Tissue-, cell-, and matrix-derived products were investigated in only 10 out of 77 included articles. Enamel-matrix derivate and PRF showed promising results pre-clinically and clinically, respectively. In general, other biological medical products than BMPs, pharmaceuticals, and tissue-, cell-, and matrix-derived products were investigated much less frequently. Outcomes of those studies demonstrated positive or diverse effects in terms of influencing hard tissue and soft tissue regeneration. Due to the low number of studies, those results do not allow conclusive assumptions. Ten out of 77 studies tested doxycycline, alendronate, simvastatin, and platelet-rich fibrin clinically in humans. Five of them were prospective clinical trials while only two clinical studies, which investigated the effects of loaded alendronate and simvastatin, used unloaded collagen scaffolds as control. Because of the low number of investigations for each substance, besides BMP-2, and the low level of evidence of studies using these substances, results might not be reliably reflecting the substances' influence on oral regeneration and need further investigation. In addition, more prospective clinical trials using appropriate study designs and higher sample sizes are needed. Still, findings of investigated substances, as well as physical properties (adsorption and release) of collagen scaffolds should be considered for further investigation and optimization. This review provides an overview of the last 15 years of scientific studies using drugloaded collagen scaffolds for oral tissue regeneration and should be considered for further research in this field.

Funding Information Open access funding provided by Medical University of Vienna.

\section{Compliance with Ethical Standards}

Conflict of Interest The authors declare that they have no competing interests.

Ethical approval This article does not contain any studies with human participants or animals performed by any of the authors.

Informed consent For this type of study, formal consent is not required.

Open Access This article is licensed under a Creative Commons Attribution 4.0 International License, which permits use, sharing, adaptation, distribution and reproduction in any medium or format, as long as you give appropriate credit to the original author(s) and the source, provide a link to the Creative Commons licence, and indicate if changes were made. The images or other third party material in this article are included in the article's Creative Commons licence, unless indicated otherwise in a credit line to the material. If material is not included in the article's Creative Commons licence and your intended use is not permitted by statutory regulation or exceeds the permitted use, you will need to obtain permission directly from the copyright holder. To view a copy of this licence, visit http://creativecommons.org/licenses/by/4.0/.

\section{References}

1. Lee S-W, Kim S-G (2014) Membranes for the guided bone regeneration. Maxillofac Plast Reconstr Surg 36:239-246. doi: 10.14402/jkamprs.2014.36.6.239

2. Ceccarelli G, Presta R, Benedetti L, Cusella de Angelis MG, Lupi SM, Rodriguez y Baena R (2017) Emerging perspectives in scaffold for tissue engineering in oral surgery. Stem Cells Int 2017: 4585401-4585411. https://doi.org/10.1155/2017/4585401

3. Albuquerque MTP, Valera MC, Nakashima M, Nör JE, Bottino MC (2014) Tissue-engineering-based strategies for regenerative endodontics. J Dent Res 93:1222-1231. https://doi.org/10.1177/ 0022034514549809

4. Chattopadhyay S, Raines RT (2014) Review collagen-based biomaterials for wound healing. Biopolymers 101:821-833. https:// doi.org/10.1002/bip.22486

5. Butler WT, Birkedal-Hansen H, Beegle WF, Taylor RE, Chung E (1975) Proteins of the periodontium. Identification of collagens with the [alpha1(I)]2alpha2 and [alpha1(III)] 3 structures in bovine periodontal ligament. J Biol Chem 250:8907-8912 
6. Kumar VA, Caves JM, Haller CA, Dai E, Liu L, Grainger S, Chaikof EL (2013) Acellular vascular grafts generated from collagen and elastin analogs. Acta Biomater 9:8067-8074. https:// doi.org/10.1016/j.actbio.2013.05.024

7. Veríssimo DM, Leitão RFC, Ribeiro RA, Figueiró SD, Sombra ASB, Góes JC, Brito GAC (2010) Polyanionic collagen membranes for guided tissue regeneration: effect of progressive glutaraldehyde cross-linking on biocompatibility and degradation. Acta Biomater 6: 4011-4018. https://doi.org/10.1016/j.actbio.2010.04.012

8. Rothamel D, Schwarz F, Sager M, Herten M, Sculean A, Becker J (2005) Biodegradation of differently cross-linked collagen membranes: an experimental study in the rat. Clin Oral Implants Res 16:369-378. https://doi.org/10.1111/j.1600-0501.2005.01108.x

9. Bottino MC, Thomas V, Schmidt G, Vohra YK, Chu TMG, Kowolik MJ, Janowski GM (2012) Recent advances in the development of GTR/GBR membranes for periodontal regeneration - a materials perspective. Dent Mater 28:703-721. https://doi.org/10. 1016/j.dental.2012.04.022

10. Nyman S, Gottlow J, Karring T, Lindhe J (1982) The regenerative potential of the periodontal ligament. An experimental study in the monkey. J Clin Periodontol 9:257-265. https://doi.org/10.1111/j. 1600-051X.1982.tb02065.x

11. Jovanovic SA, Nevins M (1995) Bone formation utilizing titanium-reinforced barrier membranes. Int J Periodontics Restorative Dent 15:56-69

12. Sculean A, Nikolidakis D, Schwarz F (2008) Regeneration of periodontal tissues: combinations of barrier membranes and grafting materials - biological foundation and preclinical evidence: a systematic review. J Clin Periodontol 35:106-116. https://doi.org/10.1111/j.1600-051X.2008.01263.x

13. Wang HL, MacNeil RL (1998) Guided tissue regeneration. Absorbable barriers. Dent Clin N Am 42:505-522

14. Ramseier CA, Rasperini G, Batia S, Giannobile WV (2012) Advanced reconstructive technologies for periodontal tissue repair. Periodontol 2000 59:185-202. https://doi.org/10.1111/j. 1600-0757.2011.00432.x

15. Higgins JPT, Thomas J, Chandler J et al (2019) Cochrane handbook for systematic reviews of interventions. https://doi.org/10. 1002/9781119536604

16. Moher D, Liberati A, Tetzlaff J, Altman DG, The PRISMA Group (2009) Preferred reporting items for systematic reviews and metaanalyses: the PRISMA statement. PLoS Med 6:e1000097. https:// doi.org/10.1371/journal.pmed.1000097

17. Miron RJ, Saulacic N, Buser D, Iizuka T, Sculean A (2013) Osteoblast proliferation and differentiation on a barrier membrane in combination with BMP2 and TGF $\beta 1$. Clin Oral Investig 17: 981-988. https://doi.org/10.1007/s00784-012-0764-7

18. He X, Liu Y, Yuan X, Lu L (2014) Enhanced healing of rat calvarial defects with MSCs loaded on BMP-2 releasing chitosan/alginate/hydroxyapatite scaffolds. PLoS One 9:e104061. https://doi.org/10.1371/journal.pone.0104061

19. Fujioka-Kobayashi M, Sawada K, Kobayashi E, Schaller B, Zhang Y, Miron RJ (2016) Recombinant human bone morphogenetic protein 9 (rhBMP9) induced osteoblastic behavior on a collagen membrane compared with rhBMP2. J Periodontol 87:e101e107. https://doi.org/10.1902/jop.2016.150561

20. Fujioka-Kobayashi M, Schaller B, Saulacic N, Pippenger BE, Zhang Y, Miron RJ (2017) Absorbable collagen sponges loaded with recombinant bone morphogenetic protein 9 induces greater osteoblast differentiation when compared to bone morphogenetic protein 2. Clin Exp Dent Res 3:32-40. https://doi.org/10.1002/ cre2.55

21. Pal P, Nguyen QC, Benton AH, Marquart ME, Janorkar AV (2019) Drug-loaded elastin-like polypeptide-collagen hydrogels with high modulus for bone tissue engineering. Macromol Biosci 19:e1900142. https://doi.org/10.1002/mabi.201900142
22. Hasegawa Y, Sato S, Takayama T, Murai M, Suzuki N, Ito K (2008) Short-term effects of rhBMP-2-enhanced bone augmentation beyond the skeletal envelope within a titanium cap in rabbit calvarium. J Periodontol 79:348-354. https://doi.org/10.1902/jop. 2008.070305

23. Seol Y-J, Kim K-H, Park Y-J, Lee YM, Ku Y, Rhyu IC, Lee SJ, Han SB, Chung CP (2008) Osteogenic effects of bonemorphogenetic-protein-2 plasmid gene transfer. Biotechnol Appl Biochem 49:85-96. https://doi.org/10.1042/BA20060247

24. Azad V, Breitbart E, Al-Zube L et al (2009) rhBMP-2 enhances the bone healing response in a diabetic rat segmental defect model. J Orthop Trauma 23:267-276. https://doi.org/10.1097/BOT. 0b013e31819f290e

25. Lee J-H, Kim C-S, Choi K-H, Jung UW, Yun JH, Choi SH, Cho KS (2010) The induction of bone formation in rat calvarial defects and subcutaneous tissues by recombinant human BMP-2, produced in Escherichia coli. Biomaterials 31:3512-3519. https:// doi.org/10.1016/j.biomaterials.2010.01.075

26. Miguez PA, Terajima M, Nagaoka H, Mochida Y, Yamauchi M (2011) Role of glycosaminoglycans of biglycan in BMP-2 signaling. Biochem Biophys Res Commun 405:262-266. https://doi. org/10.1016/j.bbrc.2011.01.022

27. Jung J-H, Yun J-H, Um Y-J, Jung UW, Kim CS, Choi SH, Cho KS (2011) Bone formation of Escherichia coli expressed rhBMP2 on absorbable collagen block in rat calvarial defects. Oral Surg Oral Med Oral Pathol Oral Radiol Endod 111:298-305. https:// doi.org/10.1016/j.tripleo.2010.05.011

28. Choi Y, Yun J-H, Kim C-S, Choi SH, Chai JK, Jung UW (2012) Sinus augmentation using absorbable collagen sponge loaded with Escherichia coli-expressed recombinant human bone morphogenetic protein 2 in a standardized rabbit sinus model: a radiographic and histologic analysis. Clin Oral Implants Res 23:682-689. https://doi.org/10.1111/j.1600-0501.2011.02222.x

29. Lai C-H, Zhou L, Wang Z-L, Lu HB, Gao Y (2013) Use of a collagen membrane loaded with recombinant human bone morphogenetic protein-2 with collagen-binding domain for vertical guided bone regeneration. J Periodontol 84:950-957. https://doi. org/10.1902/jop.2012.120415

30. Stancoven BW, Lee J, Dixon DR, McPherson JC III, Bisch FC, Wikesjö UME, Susin C (2013) Effect of bone morphogenetic protein-2, demineralized bone matrix and systemic parathyroid hormone (1-34) on local bone formation in a rat calvaria critical-size defect model. J Periodontal Res 48:243-251. https:// doi.org/10.1111/jre.12001

31. Chang Y-Y, Lee J-S, Kim M-S, Choi SH, Chai JK, Jung UW (2015) Comparison of collagen membrane and bone substitute as a carrier for rhBMP-2 in lateral onlay graft. Clin Oral Implants Res 26:e13-e19. https://doi.org/10.1111/clr.12320

32. Hwang H-D, Lee J-T, Koh J-T, Jung HM, Lee HJ, Kwon TG (2015) Sequential treatment with SDF-1 and BMP-2 potentiates bone formation in calvarial defects. Tissue Eng Part A 21:21252135. https://doi.org/10.1089/ten.TEA.2014.0571

33. Jung I-H, Lim H-C, Lee E-U, Lee JS, Jung UW, Choi SH (2015) Comparative analysis of carrier systems for delivering bone morphogenetic proteins. J Periodontal Implant Sci 45:136-144. https://doi.org/10.5051/jpis.2015.45.4.136

34. Lee C-H, Jin MU, Jung H-M, Lee JT, Kwon TG (2015) Effect of dual treatment with SDF-1 and BMP-2 on ectopic and orthotopic bone formation. PLoS One 10:e0120051. https://doi.org/10.1371/ journal.pone. 0120051

35. Lee J-S, Lee S-K, Kim B-S, Im GI, Cho KS, Kim CS (2015) Controlled release of BMP-2 using a heparin-conjugated carrier system reduces in vivo adipose tissue formation. J Biomed Mater Res A 103:545-554. https://doi.org/10.1002/jbm.a.35207

36. Mostafa NZ, Talwar R, Shahin M, Unsworth LD, Major PW, Doschak MR (2015) Cleft palate reconstruction using collagen 
and nanofiber scaffold incorporating bone morphogenetic protein in rats. Tissue Eng Part A 21:85-95. https://doi.org/10.1089/ten. tea.2014.0075

37. Yang HJ, Kim RY, Hwang SJ (2015) Pulsed electromagnetic fields enhance bone morphogenetic protein-2 dependent-bone regeneration. Tissue Eng Part A 21:2629-2637. https://doi.org/10. 1089/ten.TEA.2015.0032

38. Lee J-S, Jung G-U, Pang E-K (2016) Effects of block bone substitutes loaded with Escherichia coli-produced recombinant human bone morphogenetic protein- 2 on space maintenance and bone formation in rat calvarial onlay model. Tissue Eng Regen Med 13:311-321. https://doi.org/10.1007/s13770-016-0011-4

39. You H, Yoon S-R, Lim H-C, Lee JS, Jung UW, Choi SH (2016) Bone regenerative efficacy of limited-dose Escherichia coliderived rhBMP-2 with biphasic calcium phosphate carrier in rabbit calvarial defect model. Implant Dent 25:16-23. https://oi.org/ 10.1097/ID.0000000000000364

40. Zhang Y, Yang S, Zhou W, Fu H, Qian L, Miron RJ (2016) Addition of a synthetically fabricated osteoinductive biphasic calcium phosphate bone graft to BMP2 improves new bone formation. Clin Implant Dent Relat Res 18:1238-1247. https://doi.org/ 10.1111/cid.12384

41. Cho TH, Kim IS, Lee B, Park SN, Ko JH, Hwang SJ (2017) Early and marked enhancement of new bone quality by alendronateloaded collagen sponge combined with bone morphogenetic protein-2 at high dose: a long-term study in calvarial defects in a rat model. Tissue Eng Part A 23:1343-1360. https://doi.org/10. 1089/ten.TEA.2016.0557

42. Durham EL, Howie RN, Houck R, Oakes B, Grey Z, Hall SR, Steed M, LaRue A, Muise-Helmericks R, Cray J (2018) Involvement of calvarial stem cells in healing: a regional analysis of large cranial defects. Wound Repair Regen 26:359-365. https:// doi.org/10.1111/wrr.12658

43. Sun Y-K, Cha J-K, Thoma DS, Yoon SR, Lee JS, Choi SH, Jung UW (2018) Bone regeneration of peri-implant defects using a collagen membrane as a carrier for recombinant human bone morphogenetic protein-2. Biomed Res Int 2018:5437361-5437369. https://doi.org/10.1155/2018/5437361

44. Tenkumo T, Vanegas Sáenz JR, Nakamura K, Shimizu Y, Sokolova V, Epple M, Kamano Y, Egusa H, Sugaya T, Sasaki K (2018) Prolonged release of bone morphogenetic protein-2 in vivo by gene transfection with DNA-functionalized calcium phosphate nanoparticle-loaded collagen scaffolds. Mater Sci Eng C Mater Biol Appl 92:172-183. https://doi.org/10.1016/j.msec. 2018.06.047

45. Boyne PJ, Lilly LC, Marx RE, Moy PK, Nevins M, Spagnoli DB, Triplett RG (2005) De novo bone induction by recombinant human bone morphogenetic protein-2 (rhBMP-2) in maxillary sinus floor augmentation. J Oral Maxillofac Surg 63:1693-1707. https:// doi.org/10.1016/j.joms.2005.08.018

46. Carter TG, Brar PS, Tolas A, Beirne OR (2008) Off-label use of recombinant human bone morphogenetic protein-2 (rhBMP-2) for reconstruction of mandibular bone defects in humans. J Oral Maxillofac Surg 66:1417-1425. https://doi.org/10.1016/j.joms. 2008.01.058

47. Levin BP, Tawil P (2012) Posterior tooth replacement with dental implants in sites augmented with rhBMP-2 at time of extractiona case series. Compend Contin Educ Dent 33(104-108):110 quiz $111-112$

48. Kumar MS, Kumar MH, Vishalakshi K, Sabitha H (2016) Radiographic assessment of bone formation using rhBMP2 at maxillary periapical surgical defects: a case series. J Clin Diagn Res 10:ZR01-ZR04. https://doi.org/10.7860/JCDR/2016/11775. 7522

49. Jo D-W, Cho Y-D, Seol Y-J, Lee YM, Lee HJ, Kim YK (2019) A randomized controlled clinical trial evaluating efficacy and adverse events of different types of recombinant human bone morphogenetic protein-2 delivery systems for alveolar ridge preservation. Clin Oral Implants Res 30:396-409. https://doi.org/10. 1111/clr.13423

50. Chiu H-C, Chiang C-Y, Tu H-P, Wikesjö UME, Susin C, Fu E (2013) Effects of bone morphogenetic protein-6 on periodontal wound healing/regeneration in supraalveolar periodontal defects in dogs. J Clin Periodontol 40:624-630. https://doi.org/10.1111/ jcpe. 12075

51. Jin Q, Giannobile WV (2014) SDF-1 enhances wound healing of critical-sized calvarial defects beyond self-repair capacity. PLoS One 9:e97035. https://doi.org/10.1371/journal.pone.0097035

52. Fujioka-Kobayashi M, Kobayashi E, Schaller B, Mottini M, Miron RJ, Saulacic N (2017) Effect of recombinant human bone morphogenic protein 9 (rhBMP9) loaded onto bone grafts versus barrier membranes on new bone formation in a rabbit calvarial defect model. J Biomed Mater Res A 105:2655-2661. https:// doi.org/10.1002/jbm.a.36125

53. Saulacic N, Fujioka-Kobayashi M, Kobayashi E, Schaller B, Miron RJ (2017) Guided bone regeneration with recombinant human bone morphogenetic protein 9 loaded on either deproteinized bovine bone mineral or a collagen barrier membrane. Clin Implant Dent Relat Res 19:600-607. https://doi.org/ 10.1111/cid.12491

54. Schwarz F, John G, Kaiser T, Mihatovic I, Golubovic V, Becker J (2014) Impact of proangiogenic factors on organization and biodegradation of a collagen matrix. An immunohistochemical study in rats. Clin Oral Implants Res 25:530-538. https://doi.org/10. $1111 /$ clr.12211

55. D'Mello S, Elangovan S, Salem AK (2015) FGF2 gene activated matrices promote proliferation of bone marrow stromal cells. Arch Oral Biol 60:1742-1749. https://doi.org/10.1016/j.archoralbio. 2015.09.005

56. Lee S-H, Park Y-B, Moon H-S, Shim JS, Jung HS, Kim HJ, Chung MK (2018) The role of rhFGF-2 soaked polymer membrane for enhancement of guided bone regeneration. J Biomater Sci Polym Ed 29:825-843. https://doi.org/10.1080/09205063. 2017.1354676

57. Momose T, Miyaji H, Kato A, Ogawa K, Yoshida T, Nishida E, Murakami S, Kosen Y, Sugaya T, Kawanami M (2016) Collagen hydrogel scaffold and fibroblast growth factor- 2 accelerate periodontal healing of class II furcation defects in dog. Open Dent J 10:347-359. https://doi.org/10.2174/1874210601610010347

58. Poudel SB, Min C-K, Lee J-H, Shin YJ, Kwon TH, Jeon YM, Lee JC (2019) Local supplementation with plant-derived recombinant human FGF2 protein enhances bone formation in critical-sized calvarial defects. J Bone Miner Metab 37:900-912. https://doi. org/10.1007/s00774-019-00993-2

59. Jansen RG, van Kuppevelt TH, Daamen WF, Kuijpers-Jagtman AM, von den Hoff JW (2011) Interferon- $\gamma$-loaded collagen scaffolds reduce myofibroblast numbers in rat palatal mucosa. Eur J Orthod 33:1-8. https://doi.org/10.1093/ejo/cjp129

60. Elangovan S, D'Mello SR, Hong L et al (2014) The enhancement of bone regeneration by gene activated matrix encoding for platelet derived growth factor. Biomaterials 35:737-747. https://doi. org/10.1016/j.biomaterials.2013.10.021

61. Chang AR, Cho TH, Hwang SJ (2017) Receptor activator of nuclear factor kappa-B ligand-induced local osteoporotic canine mandible model for the evaluation of peri-implant bone regeneration. Tissue Eng Part C Methods 23:781-794. https://doi.org/10. 1089/ten.TEC.2017.0196

62. Liu H, Li M, Du L et al (2015) Local administration of stromal cellderived factor-1 promotes stem cell recruitment and bone regeneration in a rat periodontal bone defect model. Mater Sci Eng C Mater Biol Appl 53:83-94. https://doi.org/10.1016/j.msec.2015.04.002 
63. Premaraj S, Mundy BL, Morgan D, Winnard PL, Mooney MP, Moursi AM (2006) Sustained delivery of bioactive cytokine using a dense collagen gel vehicle collagen gel delivery of bioactive cytokine. Arch Oral Biol 51:325-333. https://doi.org/10.1016/j. archoralbio.2005.08.008

64. Caballé-Serrano J, Sawada K, Miron RJ, Bosshardt DD, Buser D, Gruber R (2017) Collagen barrier membranes adsorb growth factors liberated from autogenous bone chips. Clin Oral Implants Res 28:236-241. https://doi.org/10.1111/clr.12789

65. Kim J-H, Kim T-H, Kang MS, Kim H-W (2016) Angiogenic effects of collagen/mesoporous nanoparticle composite scaffold delivering VEGF165. Biomed Res Int 2016:9676934-9676938. https://doi.org/10.1155/2016/9676934

66. Cheng C-F, Lee Y-Y, Chi L-Y, Chen YT, Hung SL, Ling LJ (2009) Bacterial penetration through antibiotic-loaded guided tissue regeneration membranes. J Periodontol 80:1471-1478. https:// doi.org/10.1902/jop.2009.090044

67. Cheng C-F, Wu K-M, Chen Y-T, Hung S-L (2015) Bacterial adhesion to antibiotic-loaded guided tissue regeneration membranes - a scanning electron microscopy study. J Formos Med Assoc 114:3545. https://doi.org/10.1016/j.jfma.2013.07.010

68. Anderson TR, Marquart ME, Janorkar AV (2015) Effective release of a broad spectrum antibiotic from elastin-like polypeptidecollagen composite. J Biomed Mater Res A 103:782-790. https:// doi.org/10.1002/jbm.a.35219

69. Gamal AY, Kumper RM (2012) A novel approach to the use of doxycycline-loaded biodegradable membrane and EDTA root surface etching in chronic periodontitis: a randomized clinical trial. J Periodontol 83:1086-1094. https://doi.org/10.1902/jop.2011. 110476

70. Möller B, Wiltfang J, Acil Y, Gierloff M, Lippross S, Terheyden $H$ (2014) Prevention of the surface resorption of bone grafts by topical application of bisphosphonate on different carrier materials. Clin Oral Investig 18:2203-2211. https://doi.org/10.1007/ s00784-014-1202-9

71. De Sarkar A, Singhvi N, Shetty JN et al (2015) The local effect of alendronate with intra-alveolar collagen sponges on post extraction alveolar ridge resorption: a clinical trial. J Maxillofac Oral Surg 14:344-356. https://doi.org/10.1007/s12663-014-0633-9

72. Piao Z-G, Kim J-S, Son J-S, Lee SY, Fang XH, Oh JS, You JS, Kim SG (2014) Osteogenic evaluation of collagen membrane containing drug-loaded polymeric microparticles in a rat calvarial defect model. Tissue Eng Part A 20:3322-3331. https://doi.org/ 10.1089/ten.TEA.2013.0717

73. Edelmayer M, Al-Habbal D, Pensch M et al (2017) Effect of prolyl hydroxylase inhibitor-loaded collagen barrier membranes on osteoclastogenesis and osteoblastogenesis. J Biomater Appl 31:1370-1379. https://doi.org/10.1177/0885328217702563

74. Al-Habbal D, Janjić K, Edelmayer M et al (2018) Collagen barrier membranes do not adsorb hypoxia mimetic activity - activity of gingival fibroblasts cultured directly on collagen barrier membranes loaded with hypoxia mimetic agents. J Biomed Mater Res Part B Appl Biomater 106:874-879. https://doi.org/10.1002/ jbm.b.33893

75. Calixto JC, Lima CEV de C, Frederico L, et al. (2011) The influence of local administration of simvastatin in calvarial bone healing in rats. J Craniomaxillofac Surg 39:215-220. https://doi. org/10.1016/j.jcms.2010.03.009

76. Suthanthiran T, Annamalai S, Chellapandi S, Puthenveetil S, Dhasthaheer S, Narasimhan S (2019) Gingival crevicular fluid levels of RANKL and OPG after placement of collagen membrane with simvastatin in the treatment of intrabony defects in chronic periodontitis. J Pharm Bioallied Sci 11:S301-S304. https://doi. org/10.4103/JPBS.JPBS_18_19

77. Millán D, Jiménez RA, Nieto LE, Linero I, Laverde M, Fontanilla MR (2016) Preclinical evaluation of collagen type I scaffolds, including gelatin-collagen microparticles and loaded with a hydroglycolic Calendula officinalis extract in a lagomorph model of full-thickness skin wound. Drug Deliv Transl Res 6:57-66. https://doi.org/10.1007/s13346-015-0265-8

78. Chen Q, Cai J, Li X, Song A, Guo H, Sun Q, Yang C, Yang P (2019) Progranulin promotes regeneration of inflammatory periodontal bone defect in rats via anti-inflammation, osteoclastogenic inhibition, and osteogenic promotion. Inflammation 42:221-234. https://doi.org/10.1007/s10753-018-0886-4

79. Song W-K, Kang J-H, Cha J-K, Lee JS, Paik JW, Jung UW, Kim BH, Choi SH (2018) Biomimetic characteristics of mussel adhesive protein-loaded collagen membrane in guided bone regeneration of rabbit calvarial defects. J Periodontal Implant Sci 48:305316. https://doi.org/10.5051/jpis.2018.48.5.305

80. de Brito BB, Mendes Brazão MA, de Campos MLG et al (2012) Association of hyaluronic acid with a collagen scaffold may improve bone healing in critical-size bone defects. Clin Oral Implants Res 23:938-942. https://doi.org/10.1111/j.1600-0501. 2011.02234.x

81. Eliezer M, Sculean A, Miron RJ, Nemcovsky C, Weinberg E, Weinreb M, Zoabi H, Bosshardt DD, Fujioka-Kobayashi M, Moses O (2019) Hyaluronic acid slows down collagen membrane degradation in uncontrolled diabetic rats. J Periodontal Res 54: 644-652. https://doi.org/10.1111/jre.12665

82. Fügl A, Gasser H, Watzak G, Bucher A, Feierfeil J, Jürgens G, Watzek G, Hallström S, Gruber R (2014) S-nitroso albumin enhances bone formation in a rabbit calvaria model. Int $\mathrm{J}$ Oral Maxillofac Surg 43:381-386. https://doi.org/10.1016/j.ijom. 2013.06.018

83. Auersvald CM, Santos FR, Nakano MM, Leoni GB, de Sousa Neto MD, Scariot R, Giovanini AF, Deliberador TM (2017) The local administration of parathyroid hormone encourages the healing of bone defects in the rat calvaria: micro-computed tomography, histological and histomorphometric evaluation. Arch Oral Biol 79:14-19. https://doi.org/10.1016/j.archoralbio.2017.02.016

84. Fügl A, Gruber R, Agis H, Lzicar H, Keibl C, Schwarze UY, Dvorak G (2015) Alveolar bone regeneration in response to local application of calcitriol in vitamin D deficient rats. J Clin Periodontol 42:96-103. https://doi.org/10.1111/jcpe.12342

85. Kuchler U, Rybaczek T, Dobask T, Heimel P, Tangl S, Klehm J, Menzel M, Gruber R (2018) Bone-conditioned medium modulates the osteoconductive properties of collagen membranes in a rat calvaria defect model. Clin Oral Implants Res 29:381-388. https://doi.org/10.1111/clr.13133

86. Katagiri W, Osugi M, Kawai T, Ueda M (2013) Novel cell-free regeneration of bone using stem cell-derived growth factors. Int $\mathrm{J}$ Oral Maxillofac Implants 28:1009-1016. https://doi.org/10. 11607/jomi.3036

87. Pryor ME, Polimeni G, Koo K-T, Hartman MJ, Gross H, April M, Safadi FF, Wikesjo UME (2005) Analysis of rat calvaria defects implanted with a platelet-rich plasma preparation: histologic and histometric observations. J Clin Periodontol 32:966-972. https:// doi.org/10.1111/j.1600-051X.2005.00772.X

88. Pryor ME, Yang J, Polimeni G, Koo KT, Hartman MJ, Gross H, Agelan A, Manns JM, Wikesjö UME (2005) Analysis of rat calvaria defects implanted with a platelet-rich plasma preparation: radiographic observations. J Periodontol 76:1287-1292. https:// doi.org/10.1902/jop.2005.76.8.1287

89. Ghanaati S, Al-Maawi S, Conrad T et al (2019) Biomaterial-based bone regeneration and soft tissue management of the individualized 3D-titanium mesh: an alternative concept to autologous transplantation and flap mobilization. J Craniomaxillofac Surg 47: 1633-1644. https://doi.org/10.1016/j.jcms.2019.07.020

90. Gülșen U, Dereci Ö (2019) Evaluation of new bone formation in sinus floor augmentation with injectable platelet-rich fibrin- 
soaked collagen plug: a pilot study. Implant Dent 28:220-225. https://doi.org/10.1097/ID.0000000000000883

91. Mozgan E-M, Edelmayer M, Janjić K, Pensch M, Fischer MB, Moritz A, Agis H (2017) Release kinetics and mitogenic capacity of collagen barrier membranes supplemented with secretome of activated platelets - the in vitro response of fibroblasts of the periodontal ligament and the gingiva. BMC Oral Health 17:66. https:// doi.org/10.1186/s12903-017-0357-6

92. Miron RJ, Fujioka-Kobayashi M, Zhang Y, Sculean A, Pippenger B, Shirakata Y, Kandalam U, Hernandez M (2017) Osteogain ${ }^{\circledR}$ loaded onto an absorbable collagen sponge induces attachment and osteoblast differentiation of ST2 cells in vitro. Clin Oral Investig 21:2265-2272. https://doi.org/10.1007/s00784-0162019-5

93. Shirakata Y, Miron RJ, Nakamura T, Sena K, Shinohara Y, Horai N, Bosshardt DD, Noguchi K, Sculean A (2017) Effects of EMD liquid (Osteogain) on periodontal healing in class III furcation defects in monkeys. J Clin Periodontol 44:298-307. https://doi. org/10.1111/jcpe.12663

94. McMillan A, Nguyen MK, Gonzalez-Fernandez T, Ge P, Yu X, Murphy WL, Kelly DJ, Alsberg E (2018) Dual non-viral gene delivery from microparticles within 3D high-density stem cell constructs for enhanced bone tissue engineering. Biomaterials 161:240-255. https://doi.org/10.1016/j.biomaterials.2018.01.006

95. O'Brien FJ (2011) Biomaterials \& scaffolds for tissue engineering. Mater Today 14:88-95. https://doi.org/10.1016/S13697021(11)70058-X

96. Yang J, Shi P, Tu M, Wang Y, Liu M, Fan F, du M (2014) Bone morphogenetic proteins: relationship between molecular structure and their osteogenic activity. Food Sci Human Wellness 3:127135. https://doi.org/10.1016/j.fshw.2014.12.002

97. Lamplot JD, Qin J, Nan G, Wang J, Liu X, Yin L, Tomal J, Li R, Shui W, Zhang H, Kim SH, Zhang W, Zhang J, Kong Y, Denduluri S, Rogers MR, Pratt A, Haydon RC, Luu HH, Angeles J, Shi LL, He TC (2013) BMP9 signaling in stem cell differentiation and osteogenesis. Am J Stem Cells 2:1-21

98. Ong KL, Villarraga ML, Lau E, Carreon LY, Kurtz SM, Glassman SD (2010) Off-label use of bone morphogenetic proteins in the United States using administrative data. Spine 35:1794-1800. https://doi.org/10.1097/BRS.0b013e3181 ecf6e4

99. Kim Y-J, Lee J-Y, Kim J-E, Park JC, Shin SW, Cho KS (2014) Ridge preservation using demineralized bone matrix gel with recombinant human bone morphogenetic protein-2 after tooth extraction: a randomized controlled clinical trial. J Oral Maxillofac Surg 72:1281-1290. https://doi.org/10.1016/j.joms.2014.01.022

100. Ntounis A, Geurs N, Vassilopoulos P, Reddy M (2015) Clinical assessment of bone quality of human extraction sockets after conversion with growth factors. Int J Oral Maxillofac Implants 30: 196-201. https://doi.org/10.11607/jomi.3518

101. Clokie CML, Sándor GKB (2008) Reconstruction of 10 major mandibular defects using bioimplants containing BMP-7. J Can Dent Assoc 74:67-72

102. Moghadam HG, Urist MR, Sandor GK, Clokie CM (2001) Successful mandibular reconstruction using a BMP bioimplant. J Craniofac Surg 12:119-127 discussion 128

103. Alonso N, Tanikawa DYS, Freitas R da S, et al. (2010) Evaluation of maxillary alveolar reconstruction using a resorbable collagen sponge with recombinant human bone morphogenetic protein- 2 in cleft lip and palate patients. Tissue Eng Part C Methods 16:11831189. https://doi.org/10.1089/ten.TEC.2009.0824

104. Canan LW, da Silva FR, Alonso N et al (2012) Human bone morphogenetic protein-2 use for maxillary reconstruction in cleft lip and palate patients. J Craniofac Surg 23:1627-1633. https:// doi.org/10.1097/SCS.0b013e31825c75ba

105. Kim HJ, Chung JH, Shin SY, Shin SI, Kye SB, Kim NK, Kwon TG, Paeng JY, Kim JW, Oh OH, Kook MS, Yang HJ, Hwang SJ
(2015) Efficacy of rhBMP-2/hydroxyapatite on sinus floor augmentation: a multicenter, randomized controlled clinical trial. J Dent Res 94:158S-165S. https://doi.org/10.1177/0022034515594573

106. Kuchler U, Rudelstorfer CM, Barth B et al (2017) Crestal sinus augmentation with recombinant human bone morphogenetic protein 2: clinical and radiographic outcomes of 2-year pilot trial. Int $\mathrm{J}$ Oral Maxillofac Implants 32:e213-e220. https://doi.org/10. 11607/jomi.5536

107. Zara JN, Siu RK, Zhang X, Shen J, Ngo R, Lee M, Li W, Chiang M, Chung J, Kwak J, Wu BM, Ting K, Soo C (2011) High doses of bone morphogenetic protein 2 induce structurally abnormal bone and inflammation in vivo. Tissue Eng Part A 17:1389 1399. https://doi.org/10.1089/ten.TEA.2010.0555

108. Jensen ED, Pham L, Billington CJ et al (2010) Bone morphogenic protein 2 directly enhances differentiation of murine osteoclast precursors. J Cell Biochem 109:672-682. https://doi.org/10. $1002 /$ jcb. 22462

109. Lee K-B, Taghavi CE, Murray SS, Song KJ, Keorochana G, Wang JC (2012) BMP induced inflammation: a comparison of rhBMP-7 and rhBMP-2. J Orthop Res 30:1985-1994. https:// doi.org/10.1002/jor.22160

110. Chan DS, Garland J, Infante A, Sanders RW, Sagi HC (2014) Wound complications associated with bone morphogenetic protein-2 in orthopaedic trauma surgery. J Orthop Trauma 28: 599-604. https://doi.org/10.1097/BOT.0000000000000117

111. Schwartz Z, Simon BJ, Duran MA, Barabino G, Chaudhri R, Boyan BD (2008) Pulsed electromagnetic fields enhance BMP-2 dependent osteoblastic differentiation of human mesenchymal stem cells. J Orthop Res 26:1250-1255. https://doi.org/10.1002/jor.20591

112. Rezende ML, Consolaro A, Sant'Ana AC, Damante CA, Greghi SL, Passanezi E (2014) Demineralization of the contacting surfaces in autologous onlay bone grafts improves bone formation and bone consolidation. J Periodontol 85:e121-e129. https://doi. org/10.1902/jop.2013.130298

113. Choi B-H, Kim B-Y, Huh J-Y, Lee SH, Zhu SJ, Jung JH, Li J (2006) Cyanoacrylate adhesive for closing sinus membrane perforations during sinus lifts. J Craniomaxillofac Surg 34:505-509. https://doi.org/10.1016/j.jcms.2006.07.859

114. Baş B, Ozden B, Bekçioğlu B et al (2012) Screw fixation is superior to N-butyl-2-cyanoacrylate in onlay grafting procedure: a histomorphologic study. Int J Oral Maxillofac Surg 41:537-543. https://doi.org/10.1016/j.ijom.2011.10.025

115. de Rezende MLR, Cunha P de O, Damante CA, et al. (2015) Cyanoacrylate adhesive as an alternative tool for membrane fixation in guided tissue regeneration. J Contemp Dent Pract 16:512-518

116. Kutlu B, Tiğlı Aydın RS, Akman AC, Gümüșderelioglu M, Nohutcu RM (2013) Platelet-rich plasma-loaded chitosan scaffolds: preparation and growth factor release kinetics. J Biomed Mater Res Part B Appl Biomater 101:28-35. https://doi.org/10. 1002/jbm.b.32806

117. Marx RE, Carlson ER, Eichstaedt RM, Schimmele SR, Strauss JE, Georgeff KR (1998) Platelet-rich plasma: growth factor enhancement for bone grafts. Oral Surg Oral Med Oral Pathol Oral Radiol Endod 85:638-646

118. Miron RJ, Zucchelli G, Pikos MA, Salama M, Lee S, Guillemette V, Fujioka-Kobayashi M, Bishara M, Zhang Y, Wang HL, Chandad F, Nacopoulos C, Simonpieri A, Aalam AA, Felice P, Sammartino G, Ghanaati S, Hernandez MA, Choukroun J (2017) Use of platelet-rich fibrin in regenerative dentistry: a systematic review. Clin Oral Investig 21:1913-1927. https://doi.org/10.1007/ s00784-017-2133-z

Publisher's note Springer Nature remains neutral with regard to jurisdictional claims in published maps and institutional affiliations. 